\title{
Synthesis and Gene Silencing Properties of siRNAs Containing Terminal Amide Linkages
}

\author{
Maria Gaglione, ${ }^{1}$ M. Emilia Mercurio, ${ }^{1}$ Nicoletta Potenza, ${ }^{1}$ Nicola Mosca, ${ }^{1}$ Aniello Russo, \\ Ettore Novellino, ${ }^{2}$ Sandro Cosconati, ${ }^{1}$ and Anna Messere ${ }^{1}$ \\ ${ }^{1}$ Dipartimento Scienze e Tecnologie Ambientali, Biologiche e Farmaceutiche, Seconda Università degli Studi di Napoli, \\ Via Vivaldi 43, 81100 Caserta, Italy \\ ${ }^{2}$ Dipartimento di Chimica Farmaceutica e Tossicologica, Università “Federico II," Via D. Montesano 49, 80131 Napoli, Italy
}

Correspondence should be addressed to Sandro Cosconati; sandro.cosconati@unina2.it

and Anna Messere; anna.messere@unina2.it

Received 10 December 2013; Accepted 23 January 2014; Published 26 March 2014

Academic Editor: Daniela De Stefano

Copyright (C) 2014 Maria Gaglione et al. This is an open access article distributed under the Creative Commons Attribution License, which permits unrestricted use, distribution, and reproduction in any medium, provided the original work is properly cited.

\begin{abstract}
The active components of the RNAi are 21 nucleotides long dsRNAs containing a 2 nucleotide overhang at the $3^{\prime}$ end, carrying $5^{\prime}$-phosphate and $3^{\prime}$-hydroxyl groups (siRNAs). Structural analysis revealed that the siRNA is functionally bound at both ends to RISC. Terminal modifications are considered with interest as the introduction of chemical moieties interferes with the $3^{\prime}$ overhang recognition by the PAZ domain and the $5^{\prime}$-phosphate recognition by the MID and PIWI domains of RISC. Herein, we report the synthesis of modified siRNAs containing terminal amide linkages by introducing hydroxyethylglycine PNA (hegPNA) moieties at $5^{\prime}$, and at $3^{\prime}$ positions and on both terminals. Results of gene silencing studies highlight that some of these modifications are compatible with the RNAi machinery and markedly increase the resistance to serum-derived nucleases even after $24 \mathrm{~h}$ of incubation. Molecular docking simulations were attained to give at atomistic level a clearer picture of the effect of the most performing modifications on the interactions with the human Argonaute 2 PAZ, MID, and PIWI domains. This study adds another piece to the puzzle of the heterogeneous chemical modifications that can be attained to enhance the silencing efficiency of siRNAs.
\end{abstract}

\section{Introduction}

RNA interference (RNAi) has come into the limelight in the antisense world following the discoveries of Mello and colleagues [1] that double-stranded RNAs (dsRNAs) can elicit potent degradation of targeted $m R N A$ sequences in C. elegans and in mammalian cells $[2,3]$. The active components of the RNAi are small interfering RNAs (siRNAs), 21-22 nucleotides long dsRNA. These short species are naturally produced by Dicer-mediated cleavage of larger dsRNAs and they contain a 2 nucleotide (nt) overhang at the $3^{\prime}$ end, a $5^{\prime}$ phosphate and a $3^{\prime}$-hydroxyl group $[2,4]$. Synthetic siRNAs can also be introduced into cells in order to experimentally activate RNAi [2]. siRNA duplexes with $5^{\prime}$-hydroxyl ends are rapidly phosphorylated in cells by the cellular kinase Clp1 [5], then the siRNA strand with the thermodynamically less stable $5^{\prime}$ end is preferentially incorporated as the guiding or antisense strand (AS) in the RNA-induced silencing complex (RISC) [6], while the passenger or sense strand (SS) of the siRNA duplex is cleaved by the human Argonaute 2 protein (hAgo 2) and liberated from the complex [7]. The selection of the guide strand is then based on the thermodynamic stability of the siRNA duplex ends, the strand that is always the one whose $5^{\prime}$ end is less tightly paired to its complement. When the siRNA is fully base paired, the local thermodynamic difference (thermodynamic asymmetry) between the two $5^{\prime}$ ends favors assembly into RISC of the strand with the lower internal stability at $5^{\prime}$ end.

The Argonaute proteins are, indeed, core components of RISC and are made up by PAZ, Mid, and PIWI domains. $\mathrm{X}$-ray structural analysis $[8,9]$ revealed that the siRNA is bound at both ends: the $5^{\prime}$ end to the MID domain with some contributions from the PIWI domain and the $3^{\prime}$ end to the PAZ domain. The seed sequence is located in 
a narrow portion of the RNA binding groove. Endogenous pre-microRNAs, transcribed by cellular RNA polymerase II as single-stranded hairpin-loop RNAs, are also cleaved by Dicer to yield microRNA (miRNA) duplexes. These molecules are further processed as described for the siRNAs and incorporated in RISC by association of their guide strand to hAgo 2. Mature miRNAs play crucial roles in the regulation of gene expression during development and cell differentiation [10]. In addition, recent studies indicate that they are important regulators of virus-host interactions [11, 12].

Given its reliability and ease of use, RNAi has become the most widely used technology in functional genomics studies in vitro and in several model organisms. Nevertheless, to translate this potential into a broad new family of therapeutics, it is necessary to optimize the efficacy of the RNA-based drugs [13]. It might be possible to achieve this optimization using chemical modifications that improve, just like for antisense oligonucleotides (ASOs) [14], their in vivo stability, cellular delivery, biodistribution, pharmacokinetic, potency, and specificity [15]. In this respect, a rational design of effective chemically modified siRNA must consider as a general principle that the two strands of siRNA function differently and as practical hint that the nucleotides are different according to positions and nature. The $3^{\prime}$ and $5^{\prime}$ ends of siRNAs are critical determinants of their capacity to interfere with the unwinding of the duplex, of the incorporation of the siRNA into RISC, and of the rate of target cleavage and product release. The modifications in the terminal positions are considered with interest because the introduction of chemical moieties in these regions interferes with $3^{\prime}$ overhang recognition by the $\mathrm{PAZ}$ domain $[8,16]$ and $5^{\prime}$-phosphate recognition by the MID domain of RISC $[17,18]$.

Peptide Nucleic Acids (PNAs) are oligonucleotide mimics in which the sugar-phosphate backbone has been replaced by a pseudo-peptide backbone [19]. When used in antisense constructs, PNA confers chemical and enzymatic stability and high affinity towards complementary DNA and RNA $[19,20]$. Nonetheless, PNA have limited solubility and tendency to aggregate and are not easily internalized into cells, whereas oligonucleotide PNA (ON-PNA) chimeras are molecules with high solubility and increased capacity to cross biological membranes as compared to canonical PNA. Chimeric molecules in which tracts of DNA are bound to $\mathrm{N}$ and/or C terminus of PNA have been widely reported [21-31]. Differently from DNA-PNA chimeras, not many studies have been conducted on RNA-PNA chimeras. So far, few results have been reported for the use of RNA-PNA chimeras in RNAi, even if the advantage of mixing peptide and nucleic acids bonds has been demonstrated [27, 32-34].

In this paper we describe the synthesis of modified siRNAs containing terminal amide linkages (Figure 1). RNA$5^{\prime}$-PNA-OH (siRNA 2-4, Table 1) and RNA-5' - PNA-Ophosphate (siRNA 8-10, Table 1) were synthesized with the aim to study the impact of hydroxyethylglycine backbone (hegPNA) on silencing activity. The effect of hegPNA on both $5^{\prime}$ and $3^{\prime}$ ends of the siRNAs was also investigated by synthesizing PNA-3'-RNA-5' ${ }^{\prime}$-PNA-OH (siRNA 5-7, Table 1) and PNA-3'-RNA-5' ${ }^{\prime}$-PNA-O-phosphate (siRNA 11-13, Table 1).
Modified siRNAs containing hegPNA at $5^{\prime}$ and at $3^{\prime}, 5^{\prime}$ ends were then compared with chimeric $3^{\prime}$-PNA-OH siRNAs (siRNA 17-19, Table 1). At last, we introduced a new modification into siRNA consisting of a hegPNA monomer inserted at $5^{\prime}$ end of RNA domain by phosphodiester linkage and having at the $\mathrm{C}$-terminus a methylamide function (herein referred as " 5 ' -capped" siRNAs, 14-16 in Table 1). The biostability of 2-19 was investigated through incubation in $100 \%$ fetal bovine serum (FBS), revealing that PNA moieties on both strands of the siRNA markedly increase the resistance to serum-derived nucleases. Gene silencing studies performed in HeLa cells highlighted that the amide linkage is compatible with the RNAi machinery when placed at $3^{\prime}$ end of siRNA, in some cases improving its performances. On the other hand, amide linkage dramatically decreased the interference activity when located at $5^{\prime}$ or at both $3^{\prime}$ and $5^{\prime}$ regions of siRNAs. Interestingly, “ 5 '-capped" siRNAs partially restored the interfering effect. Finally, molecular docking simulations were engaged to give a picture of the interactions of the most performing modifications with the hAgo 2 protein.

\section{Materials and Methods}

2.1. Materials and Apparatus. SynBase CPG solid supports loading 0.040 and $0.10 \mathrm{meqg}^{-1}, 2^{\prime}$-OTBDMS-RNA phosphoramidite, PNA monomers, and standard RNA-synthesis reagents (Acetonitrile external wash (wash A), Amidite diluent, Activator solution, Cap A, Cap B, Acetonitrile wash B, Oxidizer were purchased from Link Technologies (Lanarkshire, Scotland). Standard PNA-synthesis reagents (PyBop activator, HOBT, Base solution, Cap solution, Piperidine, Deblock solution, DMF, wash B) were from Novabiochem. DMF external wash (wash A, $0.01 \% \mathrm{H}_{2} \mathrm{O}$ ) was from LabScan. All other reagents and solvents were from Sigma-Aldrich. Solid phase synthesis was performed on an ABI Expedite 8909 oligo synthesizer using standard and modified protocols. HPLC chromatographic analyses and purifications were performed on Nucleogel SAX (Macherey-Nagel, 1000-8/46) and RP-18 (Waters, C-18, $3.9 \times 300 \mathrm{~mm}$ ) columns using a Waters 600 Controller, equipped with the diode array detector Waters 996 and with Millennium software. For column chromatography, silica gel $60(0.040-0.063 \mathrm{~mm})$ from Merck was used. Centrifugations were performed on a Z $200 \mathrm{~A}$ Hermle centrifuge. Samples were lyophilized by FD4 Freeze Dryer (Heto Lab Equipment). All conjugates were analyzed by MALDI TOF mass spectrometry using a MALDI-TOF micro MX (Waters Co., Manchester, UK), equipped with a pulsed nitrogen laser $(\lambda=337 \mathrm{~nm})$. All measurements were performed using the negative detection mode. All spectra were processed and analyzed using the MassLynx 4.1 software (Waters, Milford, MA USA). LC ESI-MS analyses were performed on a MSQ mass spectrometer (ThermoElectron, Milan, Italy) equipped with an ESI source operating at $3 \mathrm{kV}$ needle voltage $\left(T=320^{\circ} \mathrm{C}\right)$ and with a complete Surveyor HPLC system, comprising a MS pump, an autosampler, and a PDA detector. All buffers were prepared from highly purified Milli Q water and made RNase-free by treatment with DEPC (diethylpirocarbonate) (Sigma Aldrich). UV measurements 


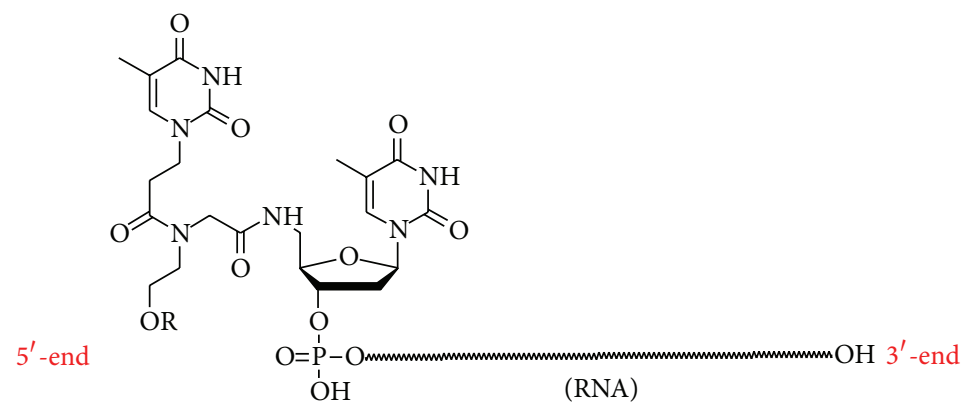

$\mathrm{R}=\mathrm{H}$ in $\mathbf{C}$ and $\mathbf{D}$

$\mathrm{R}=$ phosphate in $\mathbf{G}$ and $\mathbf{H} \quad$ Structure of $\mathbf{C}, \mathbf{D}, \mathbf{G}$, and $\mathbf{H}$

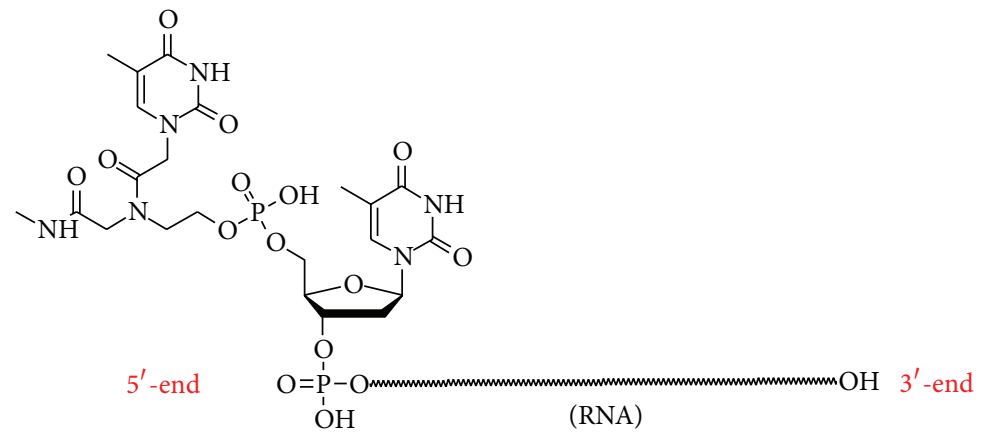

Structure of $\mathbf{M}$ and $\mathbf{N}$

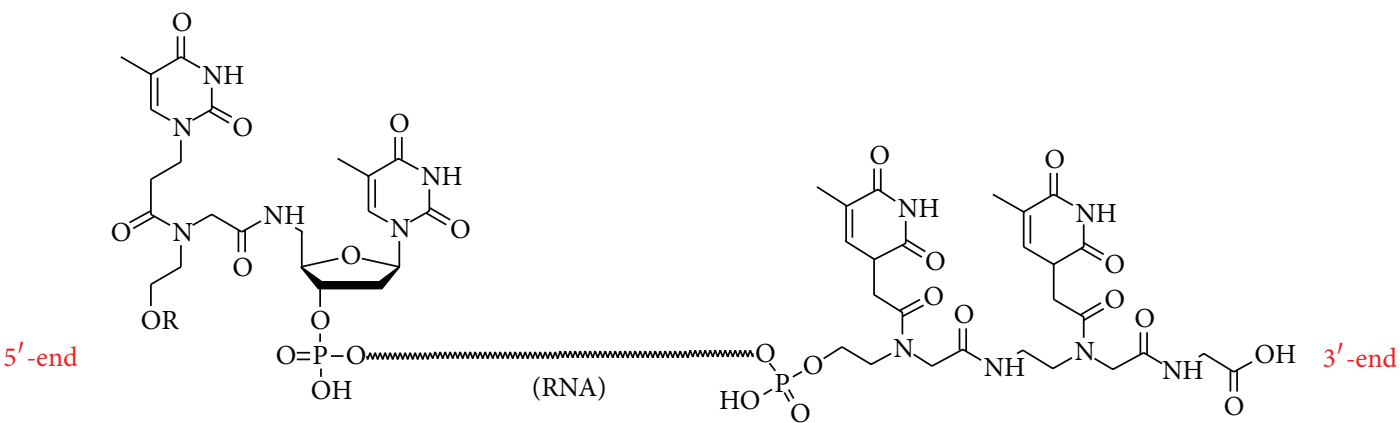

$\mathrm{R}=\mathrm{H}$ in $\mathbf{E}$ and $\mathbf{F}$

$\mathrm{R}=$ phosphate in $\mathbf{I}$ and $\mathbf{L} \quad$ Structure of $\mathbf{E}, \mathbf{F}, \mathbf{I}$, and $\mathbf{L}$

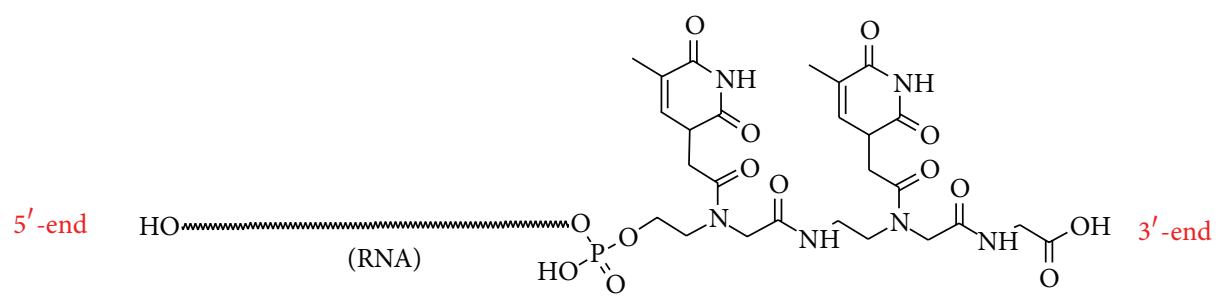

Structure of $\mathbf{O}$ and $\mathbf{P}$

FIGURE 1: Structure of the RNA oligomers forming modified siRNAs 2-19.

and melting curves of duplexes $(1.0 \mu \mathrm{M})$ were acquired on a Jasco V-550 spectrophotometer equipped with a Jasco ETC-505T Peltier temperature programmer using a $1 \mathrm{~cm}$ path-length quartz cell (Hellma). The concentrations were estimated spectrophotometrically at $90^{\circ} \mathrm{C}$ using the following additive molar extinction coefficient $\varepsilon^{260}\left(\mathrm{~L} \mathrm{~cm}^{-1} \mathrm{~mol}^{-1}\right), T=$ 8800, $A=15400, C=7200, G=11500$, and $U=9900$ for the natural nucleobases and $t=8600$ for the PNA monomers. Oligomers were suspended in RNase-free annealing buffer (100 $\mathrm{mM}$ potassium acetate, $30 \mathrm{mM}$ Hepes- $\mathrm{KOH}, \mathrm{pH}=7.4$, and $2 \mathrm{mM}$ magnesium acetate) and equimolar ratios of the sense and antisense strands were annealed to form the duplexes to a final concentration of $25 \mu \mathrm{M}$ by incubation at $90^{\circ} \mathrm{C}$ for $1 \mathrm{~min}$ and gradually cooling to room temperature. 
TABLE 1

\begin{tabular}{|c|c|c|c|c|}
\hline & siRNA sequence & siRNAs & $\operatorname{Tm}^{\circ} \mathrm{C}$ & $\Delta$ \\
\hline $\mathbf{a}$ & AS $^{\prime}$ TTGCAUGCGCCUUAUGAAGCU5 ${ }^{\prime}$ & \multirow{2}{*}{ siRNA 1 wt } & \multirow{2}{*}{76} & \multirow{2}{*}{ - } \\
\hline b & SS 5'CGUACGCGGAAUACUUCGATT3' & & & \\
\hline $\mathrm{C}$ & 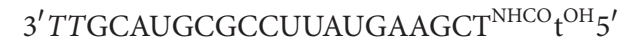 & \multirow{2}{*}{ siRNA 2} & \multirow{2}{*}{65} & \multirow{2}{*}{-1} \\
\hline b & 5'CGUACGCGGAAUACUUCGATT3' & & & \\
\hline a & $3^{\prime}$ TTGCAUGCGCCUUAUGAAGCU5' & \multirow{2}{*}{ siRNA 3} & \multirow{2}{*}{65} & \multirow{2}{*}{-11} \\
\hline D & $5^{\prime \mathrm{OH}_{\mathrm{t}}{ }^{\mathrm{CONH}} \text { TCGUACGCGGAAUACUUCGATT3 }}{ }^{\prime}$ & & & \\
\hline $\mathrm{C}$ & $3^{\prime}$ TTGCAUGCGCCUUAUGAAGCT ${ }^{\mathrm{NHCO}_{\mathrm{t}} \mathrm{OH}_{5}^{\prime}}$ & \multirow{2}{*}{ siRNA 4} & \multirow{2}{*}{65} & \multirow{2}{*}{-11} \\
\hline $\mathbf{D}$ & 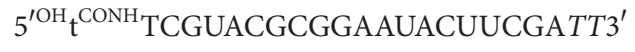 & & & \\
\hline $\mathbf{E}$ & $3^{\prime} t t$ GCAUGCGCCUUAUGAAGCT ${ }^{\mathrm{NHCO}_{\mathrm{t}} \mathrm{OH}_{5}^{\prime}}$ & \multirow{2}{*}{ siRNA 5} & \multirow{2}{*}{66} & \multirow{2}{*}{-10} \\
\hline b & 5'CGUACGCGGAAUACUUCGATT3' & & & \\
\hline a & 3'TTGCAUGCGCCUUAUGAAGCU5' & \multirow{2}{*}{ siRNA 6} & \multirow{2}{*}{66} & \multirow{2}{*}{-10} \\
\hline $\mathbf{F}$ & 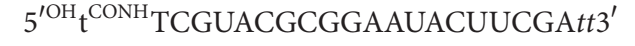 & & & \\
\hline $\mathbf{E}$ & $3^{\prime} t t$ GCAUGCGCCUUAUGAAGCT ${ }^{\mathrm{NHCO}_{\mathrm{t}} \mathrm{OH}^{\prime}}$ & \multirow{2}{*}{ siRNA 7} & \multirow{2}{*}{66} & \multirow{2}{*}{-10} \\
\hline $\mathbf{F}$ & $5^{\prime \mathrm{OH}_{\mathrm{t}}{ }^{\mathrm{CONH}} \text { TCGUACGCGGAAUACUUCGA } t 3^{\prime}}$ & & & \\
\hline G & $3^{\prime}$ TTGCAUGCGCCUUAUGAAGCT ${ }^{\mathrm{NHCO}} \mathrm{t}^{\mathrm{OP}} 5^{\prime}$ & \multirow{2}{*}{ siRNA 8} & \multirow{2}{*}{67} & \multirow{2}{*}{-9} \\
\hline b & 5'CGUACGCGGAAUACUUCGATT3' & & & \\
\hline $\mathbf{a}$ & $3^{\prime}$ TTGCAUGCGCCUUAUGAAGCU5' & \multirow{2}{*}{ siRNA 9} & \multirow{2}{*}{66} & \multirow{2}{*}{-10} \\
\hline $\mathbf{H}$ & $5^{\prime \mathrm{PO}} \mathrm{t}^{\mathrm{CONH}}$ TCGUACGCGGAAUACUUCGATT3' & & & \\
\hline G & 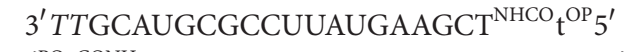 & siRNA 10 & 67 & -9 \\
\hline $\mathbf{H}$ & $5^{\prime \mathrm{PO}} \mathrm{t}^{\mathrm{CONH}}$ TCGUACGCGGAAUACUUCGATT3' & & & \\
\hline I & $3^{\prime} t t G C A U G C G C C U U A U G A A G C T^{N H C O} t^{\mathrm{OP}} 5^{\prime}$ & siRNA 11 & 66 & -10 \\
\hline b & 5'CGUACGCGGAAUACUUCGATT3' & SIKINA II & & \\
\hline $\mathbf{a}$ & 3'TTGCAUGCGCCUUAUGAAGCU5' & siRNA 12 & 68 & -8 \\
\hline $\mathbf{L}$ & 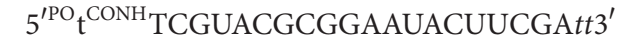 & SIKINA 12 & 00 & $-\mathbf{o}$ \\
\hline I & 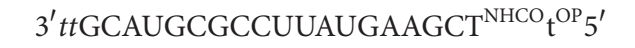 & siRNA 13 & 66 & -10 \\
\hline $\mathbf{L}$ & $5^{\prime \mathrm{PO}} \mathrm{t}^{\mathrm{CONH}}$ TCGUACGCGGAAUACUUCGA $t+3^{\prime}$ & SINAT & 00 & -10 \\
\hline M & $3^{\prime}$ TTGCAUGCGCCUUAUGAAGCTt $^{\mathrm{CONHCH}_{3}} 5^{\prime}$ & siRNA 14 & 70 & -6 \\
\hline b & 5'CGUACGCGGAAUACUUCGATT3' & & & \\
\hline a & 3'TTGCAUGCGCCUUAUGAAGCU5' & siRNA 15 & 68 & -8 \\
\hline $\mathbf{N}$ & 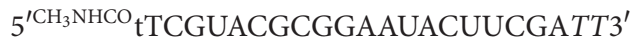 & SIKINA 15 & 08 & -8 \\
\hline M & $3^{\prime} \mathrm{TTGCAUGCGCCUUAUGAAGCTt}^{\mathrm{CONHCH}_{3}} 5^{\prime}$ & siRNA 16 & 70 & -6 \\
\hline $\mathbf{N}$ & 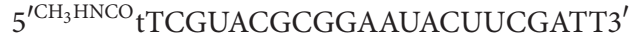 & & & \\
\hline $\mathbf{O}$ & $3^{\prime} t t$ GCAUGCGCCUUAUGAAGCU5 ${ }^{\prime}$ & siRNA 17 & 76 & - \\
\hline b & $5^{\prime}$ CGUACGCGGAAUACUUCGATT3' & & & \\
\hline a & $3^{\prime}$ TTGCAUGCGCCUUAUGAAGCU5' & siRNA 18 & 76 & - \\
\hline $\mathbf{P}$ & 5'CGUACGCGGAAUACUUCGAtt3' & S1RINA 18 & 10 & - \\
\hline O & $3^{\prime} t t$ GCAUGCGCCUUAUGAAGCU5' & siRNA 19 & 76 & - \\
\hline $\mathbf{P}$ & $5^{\prime}$ CGUACGCGGAAUACUUCGA $t+3^{\prime}$ & & 10 & - \\
\hline
\end{tabular}

Melting curves were recorded at $260 \mathrm{~nm}$ using a heating rate of $0.5^{\circ} \mathrm{C} / \mathrm{min}$, a slit of $2 \mathrm{~nm}$, and a response of $0.2 \mathrm{~s}$. Tm values were obtained from the maxima of the first derivatives of the melting curves. Circular Dichroism spectra of the siRNA samples $(1.0 \mu \mathrm{M})$ were recorded at $15^{\circ} \mathrm{C}$ using a $1 \mathrm{~cm}$ quartz cell in the Jasco J-815 spectropolarimeter equipped with a PFD-425S thermal controller unit. ${ }^{31} \mathrm{P}$ NMR spectrum was recorded at $161.98 \mathrm{MHz}$ on a Bruker WM-400 spectrometer using $85 \% \mathrm{H}_{3} \mathrm{PO}_{4}$ as external standard.

2.2. General Procedures for RNA Oligomers Synthesis. All oligomers were synthesized on ABI Expedite 8909 oligo synthesizer by using standard and modified protocols $(1 \mu \mathrm{M}$ scale), $2^{\prime}$-OTBDMS-RNA phosphoramidite monomers, and standard RNA synthesis reagents. Unmodified RNAs a and b were prepared on SynBase CPG solid support (CPG$\mathrm{OH}$, loading $0.04 \mathrm{meq}^{-1}$ ) (a: calculated mass 6646,1, found 6645.9; b: calculated mass 6669.1, found 6667.8).

The RNA oligomers $\mathbf{C}$ and $\mathbf{D}$ were synthesized using last coupling monomer $5^{\prime}$-MMT-amino-T phosphoramidite. After deprotection (2\% DCA in DCM), the $5^{\prime}$-amino group of oligomer was coupled to 2-(N-(2-((4-methoxyphenyl)diphenylmethoxy)ethyl)-2-(5-methyl-2,4-dioxo-3,4-dihydropyrimidin-1(2H)-yl)acetamido) acetic acid $(0.2 \mathrm{M}$ in 
DMF) [35] by using a solution 0.2 M HATUin DMF, 0.2 M DIPEA, and 0.3 M lutidine in DMF. The coupling cycle was carried out by a procedure slightly modified with respect to the standard PNA synthesis protocols in the steps of washing and deblocking as described here: (1) washing with $2.5 \mathrm{~mL}$ of (ACN/DMF) $(1: 1, \mathrm{v} / \mathrm{v})$; (2) coupling 20 minutes; (3) washing with $2.5 \mathrm{~mL}$ of ACN/DMF $(1: 1, \mathrm{v} / \mathrm{v})$; (4) capping with $5 \%$ of acetic anhydride and $6 \%$ of 2,6-lutidine in DMF, $2.0 \mathrm{~mL}$; (5) washing with $2.5 \mathrm{~mL}$ of ACN/DMF $(1: 1, \mathrm{v} / \mathrm{v})$ and $2.5 \mathrm{~mL}$ of DMF; (6) deblocking with a solution of dichloroacetic acid (2\%) in ACN; (7) washing with $2.5 \mathrm{~mL}$ of DMF and $5 \mathrm{~mL}$ of ACN (C: calculated mass 6910.2, found 6910.0; D: calculated mass 7240.4, found 7238.0).

The RNA oligomers $\mathbf{E}$ and $\mathbf{F}$ were grown on the support VIII, following the same procedures described for the $5^{\prime}$ terminal modification of the oligomers $\mathbf{C}$ and $\mathbf{D}$ (E: calculated mass 6958.9, found 6957.7; F: calculated mass 7288.1, found 7286.9).

The RNA oligomers $\mathbf{G}$ and $\mathbf{H}$ were prepared after solid phase phosphorylation of the oligomers $\mathbf{C}$ and $\mathbf{D}$. The phosphorylation reaction was achieved by using a solution $0.1 \mathrm{M}$ of chemical phosphorylation reagent [36] in ACN with $0.3 \mathrm{M}$ BTT in ACN. The oxidation was achieved by treatment with $\mathrm{I}_{2} / \mathrm{H}_{2} \mathrm{O} / \mathrm{Py}$ (G: calculated mass 6990.2, found 6988.9; $\mathrm{H}$ : calculated mass 7320.3, found 7319.1).

The RNA oligomers I and $\mathbf{L}$ were synthesized on support VIII, following the same procedures described for $5^{\prime}$ terminal couplings and phosphorylation of the oligomers $\mathbf{G}$ and $\mathbf{H}$ (I: calculated mass 7038.9, found 7037.7; L: calculated mass 7368.1, found 7366.9).

The RNA oligomers $\mathbf{M}$ and $\mathbf{N}$ were prepared on standard SynBase CPG support, by introducing derivative $\mathbf{X}$ as last coupling monomer. The last coupling was carried out on automated synthesizer with a $0.1 \mathrm{M}$ solution of derivative $\mathbf{X}$ in ACN (double coupling) and by using 0.3 M BTT in ACN, as activating solution. All succeeding procedures followed the standard protocol for RNA synthesis (M: calculated mass 7004.1, found 7002.8; N: calculated mass 7334.3, found 7333.1).

The RNA oligomers $\mathbf{O}$ and $\mathbf{P}$ were grown on support VIII, following the standard protocol for RNA synthesis (O: calculated mass 6693.8, found 6692.6; P: calculated mass 6716.8 , found 6715.0$)$.

2.3. Synthesis of Derivative VI. $572 \mathrm{mg}$ of SynBase CPG solid supports (CPG-OH, high loading $0.10 \mathrm{meqg}^{-1}$ ) were functionalized with $297 \mathrm{mg}(1.0 \mathrm{mmol})$ of Fmoc-Gly-OH using PyBOP (520 mg, $1.0 \mathrm{mmol}$ ) and HOBT (153 mg, $1.0 \mathrm{mmol})$ as activating agents in dry DMF $(6 \mathrm{~mL})$. The mixture was kept at $r$. t. for $16 \mathrm{~h}$ under shaking. The support was filtered and washed with $\mathrm{DMF}$ and $\mathrm{Et}_{2} \mathrm{O}$ and then dried under reduced pressure, thus obtaining support III $(0.089 \mathrm{mmol} / \mathrm{g}, 89 \%$ coupling yield $)$. The yield of incorporation of the glycine residue was calculated by quantitative UV measurements $(301 \mathrm{~nm})$ of the fluorene derivative released by piperidine/DMF $(1: 4, \mathrm{v} / \mathrm{v})$ treatment of weighed amounts of support. Gly-linking support was washed with pyridine and then treated with acetic anhydride in pyridine $(6.0 \mathrm{~mL}, 2: 3, \mathrm{v} / \mathrm{v}, 1 \mathrm{~h}, \mathrm{r.t}$.$) to block the unreacted$ hydroxy groups. After deblocking of amino function of supported glycine by a solution of piperidine in DMF (20\%), 2-(N-(2-((4-methoxyphenyl)diphenylmethoxy)ethyl)-2-(5methy-2,4-dioxo-3,4-dihydropyrimidin-1(2H)-yl)acetamido) acetic acid (0.2 $\mathrm{M}$ in DMF) [35] was coupled by a solution 0.2 M HATUin DMF, 0.2 M DIPEA, and $0.3 \mathrm{M}$ lutidine in DMF. The coupling cycle was carried out by a slightly modified procedure consisting of the following steps: (1) washing with $2.5 \mathrm{~mL}$ of (ACN/DMF) $(1: 1, \mathrm{v} / \mathrm{v}) ;(2)$ coupling 20 minutes; (3) washing with $2.5 \mathrm{~mL}$ of ACN/DMF $(1: 1, \mathrm{v} / \mathrm{v})$; (4) capping with $5 \%$ of acetic anhydride and $6 \%$ of 2,6-lutidine in DMF, $2.0 \mathrm{~mL}$; (5) washing with $2.5 \mathrm{~mL}$ of ACN/DMF $(1: 1, \mathrm{v} / \mathrm{v})$ and $2.5 \mathrm{~mL}$ of DMF; (6) deblocking with a solution of dichloroacetic acid (2\%) in DCA; (7) washing with $2.5 \mathrm{~mL}$ of DMF and $5 \mathrm{~mL}$ of $\mathrm{ACN}$ ( 0.089 meq $^{-1}, 100 \%$ coupling yield). The phosphorylation reaction was achieved $\left(0.088 \mathrm{meq}^{-1}, 99 \%\right.$ coupling yield $)$ by using a solution $0.1 \mathrm{M}$ of chemical phosphorylation reagent in ACN with 0.3 M BTT in ACN. The oxidation was achieved by treatment with $\mathrm{I}_{2} / \mathrm{H}_{2} \mathrm{O} / \mathrm{Py}$. After ammonium hydroxide treatment and purification by $\mathrm{C} 18$ Sep-Pak columns eluted by water/ACN $(7: 3, \mathrm{v}: \mathrm{v})$ derivative VI was isolated and characterized (ESI-MS: $\mathrm{m} / \mathrm{z}=940.267\left[\mathrm{M}-2 \mathrm{H}^{+}+2 \mathrm{Na}^{+}\right]$, calculated for $\mathrm{C}_{41} \mathrm{H}_{49} \mathrm{~N}_{6} \mathrm{O}_{15} \mathrm{P}: 896,30 ;{ }^{31} \mathrm{P}$ NMR $\delta$ : 1.846).

2.4. Functionalization of the CPG Resin: Support VIII. FmocGly-OH (60 mg, $0.2 \mathrm{mmol}$ ), PyBop (104 mg, $0.2 \mathrm{mmol}$ ), and HOBt $(30 \mathrm{mg}, 0.2 \mathrm{mmol})$ in dry DMF $(5.0 \mathrm{~mL})$ were added to CPG-OH resin (500 mg, $0.04 \mathrm{meq}^{-1}$ of hydroxy groups), previously washed with DMF. The mixture was kept at r.t. with shaking for $24 \mathrm{~h}$. The support was filtered and washed with DMF and $\mathrm{Et}_{2} \mathrm{O}$ and then dried under reduced pressure, thus providing functionalized CPG $(0.035 \mathrm{mmol} / \mathrm{g}$, $89 \%$ coupling yield). The yield of incorporation of the glycine residue was calculated by quantitative UV measurements $(301 \mathrm{~nm})$ of the fluorene derivative released by piperidine/DMF $(1: 4, \mathrm{v} / \mathrm{v})$ treatment of weighed amounts of support. Gly-linking support was washed with pyridine and then treated with acetic anhydride in pyridine $(6.0 \mathrm{~mL}$, $2: 3, \mathrm{v} / \mathrm{v}, 10 \mathrm{~min}$, r.t.) to block the unreacted hydroxy groups. After deblocking of amino function of supported glycine by a solution of piperidine in DMF (20\%), N(Thymin-1-ylacetyl)-N-(2-Fmoc-aminoethyl)glycine (53 mg, $0.2 \mathrm{mmol}$ ) was reacted in DMF and in presence of HATU (76 mg, $0.2 \mathrm{mmol})$ and DIPEA $(52 \mu \mathrm{L}, 0.3 \mathrm{mmol})$ for $1 \mathrm{~h}$ at r.t. with shaking. The coupling yields, measured as previously described, were $90 \% \quad(0.031 \mathrm{mmol} / \mathrm{g})$. A capping procedure was carried out, after washing with DMF, by the addition of acetic anhydride in pyridine $(2: 3, \mathrm{v} / \mathrm{v}, 1 \mathrm{~h}$, r.t.). After deblocking of amino function of supported PNA by a solution of piperidine in DMF $(20 \%)$, 2-(N-(2-((4-methoxyphenyl)diphenylmethoxy)ethyl)-2-(5methyl-2,4-dioxo-3,4-dihydropyrimidin-1(2H)-yl)acetamido) acetic acid [35] (0.2 M in DMF) was coupled by a solution $0.2 \mathrm{M}$ HATUin DMF, 0.2 M DIPEA, and $0.3 \mathrm{M}$ lutidine in DMF. The coupling cycle was carried out by a slightly modified procedure consisting in the following 
steps: (1) washing with $2.5 \mathrm{~mL}$ of (ACN/DMF) $(1: 1, \mathrm{v} / \mathrm{v}) ;(2)$ coupling 20 minutes; (3) washing with $2.5 \mathrm{~mL}$ of ACN/DMF $(1: 1, \mathrm{v} / \mathrm{v}) ;(4)$ capping with $5 \%$ of acetic anhydride and $6 \%$ of 2,6-lutidine in DMF, $2.0 \mathrm{~mL}$; (5) washing with $2.5 \mathrm{~mL}$ of ACN/DMF (1:1, v/v) and $2.5 \mathrm{~mL}$ of DMF. The obtained support VIII resulted in $0.031 \mathrm{meq}^{-1}$ (100\% coupling yield) as judged by quantitative UV measurements $(478 \mathrm{~nm})$ of the MMT cation released by dichloroacetic acid (2\%) in DCM treatment of weighed amounts of VIII.

2.5. Synthesis of Derivative $\boldsymbol{X}$. Methyl ester derivative of hegPNA IX (0.50 g; $1.67 \mathrm{mmol})$ was dissolved in anhydrous DCM (15 mL). Anhydrous DIEA (0.63 mL, $3.69 \mathrm{mmol})$ and 2-cyanoethyl-N,N-diisopropylphosphoramidochloridite $(0.24 \mathrm{~mL} ; 1.10 \mathrm{mmol})$ were added to this solution. After $1 \mathrm{~h}$ the solvent was evaporated in vacuo and the residue dissolved in EtOAc and washed four times with brine. The organic phase was dried and evaporated in vacuo. The residue was purified by column chromatography on silica gel using DCM/EtOAc/ $\mathrm{N}_{3}$ Et, $(49.5: 49.5: 1, \mathrm{v}: \mathrm{v}: \mathrm{v})$ as the eluent. $0.65 \mathrm{~g}$ (78\% yield) of derivative $\mathbf{X}$ was obtained $\left({ }^{31} \mathrm{P}-\mathrm{NMR}\left(\mathrm{CDCl}_{3}\right)\right.$ $\delta: 146.0,146.7)$.

2.6. Cell Cultures, Transfections, and Luciferase Assay. HeLa cells were grown at $37^{\circ} \mathrm{C}, 5 \% \mathrm{CO}_{2}$ in Dulbecco's modified Eagle's medium supplemented with $10 \%$ fetal bovine serum (FBS) (EuroClone), 100 units $\mathrm{mL}^{-1}$ penicillin, and $100 \mathrm{mg} \mathrm{mL}^{-1}$ streptomycin (EuroClone). The day before transfection, cells were trypsinized, diluted in the appropriate amount of growth medium without antibiotics, and transferred to 12 -well plates ( $1 \mathrm{~mL}$ per well) such that they were 80-90\% confluent at the time of transfection. Cotransfections of reporter plasmids (per well $1 \mu \mathrm{g}$ pGL2-control, encoding the firefly Photinus pyralis luciferase and $0.05 \mu \mathrm{g}$ phRLTK, encoding Renilla reniformis luciferase, Promega) and $10 \mathrm{nM}$ siRNAs were carried out with Lipofectamine2000 (Invitrogen) as described by the manufacturer. Luciferase activities were monitored 2 days after transfection using Dual-Luciferase Reporter Assay System (Promega) according to the manufacturer's protocol. The firefly luciferase activity was normalized to the Renilla luciferase activity and the uninhibited activity (plasmids encoding the luciferases cotransfected with unrelated siRNA as control) was set to 1 . Data represent mean normalized luciferase activity from at least three experiments \pm s.d.

2.7. Stability of siRNAs in $100 \%$ FBS. $7.5 \mu \mathrm{L}$ of unmodified and modified siRNAs $(20 \mu \mathrm{M})$ were incubated with $75 \mu \mathrm{L}$ of FBS at $37^{\circ} \mathrm{C}$. Aliquots of $22 \mu \mathrm{L}$ ( 40 pmoles) were withdrawn at different time points and immediately frozen. The solutions were then extracted with phenol and siRNAs were precipitated with ethanol. Samples were subjected to electrophoresis in $15 \%$ polyacrylamide-tris-borate-EDTA (TBE) under nondenaturing conditions and visualized by ethidium bromide staining. Equal amounts of siRNAs before serum incubation were extracted with phenol and loaded as controls. Gel images were captured by ChemiDoc XRS (Bio-Rad) and RNA electrophoretic bands were quantified by Image Lab software
(Bio-Rad). Signal intensity value of the intact siRNA was set at 1 .

2.8. Molecular Docking. The miR-20a/hAgo 2 threedimensional structure was downloaded from the Protein Data Bank (PDB code 4F3T) [9]. The co-crystal RNA present in this structure was used as template for the construction of the modified siRNAs featuring the modifications at the 5' and 3' end (viz. AS, antisense strand, of siRNAs 16 and 17, resp.).). SiRNA structures were built using the builder in the Maestro package of Schroedinger Suite 2010 and optimized using a version of MacroModel also included. The following parameters of energy minimization were used: OPLS2005 force field was used, water was used as an implicit solvent, and a maximum of 5000 iterations of the Polak-Ribier conjugate gradient minimization method was used with a convergence threshold of $0.01 \mathrm{~kJ} \mathrm{~mol}^{-1} \AA^{-1}$.

The new version of the docking program AutoDock4.2 (AD4) $[37,38]$, as implemented through the graphical user interface called AutoDockTools (ADT), was used to dock these siRNAs. The constructed compounds and the receptor structure were converted to AD4 format files using ADT generating automatically all other atom values. Since AD4 has a limit in the number of ligand rotatable bonds only the PNAs (viz. dTdTa, dTdTb, and dTdTc) were free to rotate. The docking area was centered around the putative binding site (PAZ domain for $\mathbf{1 7}$ and MID domain for 16). A set of grids of $90 \AA \times 40 \AA \times 75 \AA$ with $0.375 \AA$ spacing was calculated around the docking area for the ligand atom types using AutoGrid4.2. For each ligand, 700 separate docking calculations were performed. Each docking calculation consisted of 25 million energy evaluations using the Lamarckian genetic algorithm local search (GALS) method. The GALS method evaluates a population of possible docking solutions and propagates the most successful individuals from each generation into the subsequent generation of possible solutions. A low-frequency local search according to the method of Solis and Wets is applied to docking trials to ensure that the final solution represents a local minimum. All dockings described in this paper were performed with a population size of 250 , and 300 rounds of Solis and Wets local search were applied with a probability of 0.06 . A mutation rate of 0.02 and a crossover rate of 0.8 were used to generate new docking trials for subsequent generations, and the best individual from each generation was propagated over the next generation. The docking results from each of the 700 calculations were clustered on the basis of root-mean square deviation ( $\mathrm{rmsd}$ ) (solutions differing by less than $3.0 \AA$ ) between the cartesian coordinates of the atoms and were ranked on the basis of free energy of binding $\left(\Delta \mathrm{G}_{\mathrm{AD} 4}\right)$. These lowest energy conformations were visually inspected for good chemical geometry. Because AD4 does not perform any structural optimization and energy minimization of the complexes found, a molecular mechanics/energy minimization (MM/EM) approach was applied to refine the AD4 output using the Schroedinger Suite 2010. The computational protocol applied consisted of the application of 100000 steps of the Polak-Ribiére conjugate gradients (PRCG) or until the derivative convergence was 

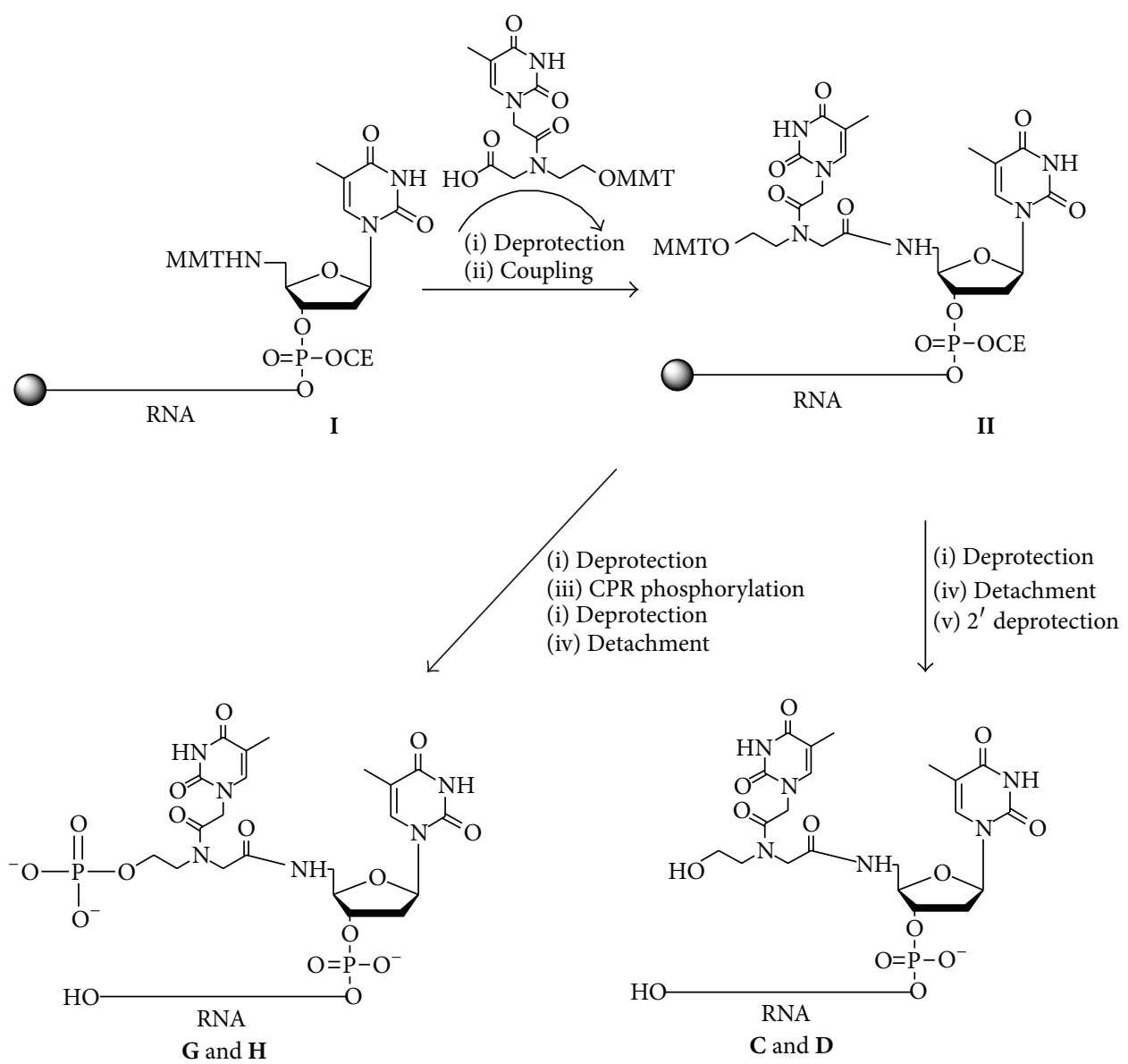

Figure 2: Assembling of the RNA oligomers C, D, G, and H. Reagents and conditions: (i) 2\% DCA in DCM; (ii) 0.2 M HATU in DIPEA/DMF; (iii) $0.1 \mathrm{M}$ CPR in ACN, $0.3 \mathrm{M}$ BTT in $\mathrm{ACN}$; (iv) $\mathrm{NH}_{4} \mathrm{OH}, 50^{\circ} \mathrm{C}, 12 \mathrm{~h}$; (v) $\mathrm{Et}_{3} \mathrm{~N} \cdot 3 \mathrm{HF}$ in DMF 1:3 v/v, $65^{\circ} \mathrm{C}, 150 \mathrm{~min}$.

$0.05 \mathrm{~kJ} / \mathrm{mol}$. All complexes pictures were rendered employing the UCSF Chimera software [39].

\section{Results}

\subsection{Chemistry}

3.1.1. Synthesis of Unmodified siRNA 1 and Modified siR$N A s$ 2-4. In the present work our attention was mainly focused on specific chemical modification at $5^{\prime}$ region of the antisense and sense strands of siRNAs. In this respect, we decided to modify an siRNA targeting firefly luciferase mRNA [2] because of the possibility of testing it by an automated luciferase assay allowing an easy and accurate judgment of the gene silencing activity in cultured mammalian cells, thus comparing chemically modified siRNAs to the unmodified one. Unmodified RNA strands $\mathbf{a}-\mathbf{b}$ in Table 1 (antisense $5^{\prime}$-UCGAAGUAUUCCGCGUACGTT- $3^{\prime}$ and sense $5^{\prime}$-CGUACGCGGAAUACUUCGATT- $3^{\prime}$ ) were synthesized following DNA/RNA fully automated protocols. The synthesis of the RNA-5' $-\mathrm{PNA}-\mathrm{OH}$ C-D was carried out on CPG-OH support using commercially available $2^{\prime}$-O-TBDMS- $3^{\prime}$-phosphoramidite ribonucleotides and
$5^{\prime}$-MMT-NH-thymidine-3'-O-phosphoramidite. MMT-hydroxyethylglycine PNA monomers (MMT-O-PNA) were synthesized following reported procedures and characterized by ${ }^{1} \mathrm{H}$ and ${ }^{13} \mathrm{C}$ NMR spectroscopies [35]. The synthesis of the RNA tract was performed on a RNA synthesizer and $5^{\prime}$-MMT-NH-thymidine- $3^{\prime}$-O-phosphoramidite was introduced as last coupling monomer to obtain support I (Figure 2). In order to incorporate the PNA monomer at $5^{\prime}$ end of RNA sequence (support II, Figure 2), MMThydroxyethylglycine PNA monomer was coupled using PNA standard procedure (HATU in DIPEA/DMF).

After deblocking of the hydroxyl function by $2 \%$ DCA/DCM treatment, the oligomers were cleaved from the support by treatment with $\mathrm{NH}_{4} \mathrm{OH}$ at $50^{\circ} \mathrm{C}$ overnight. The $2^{\prime}$-O-TBDMS protecting group was removed by $\mathrm{Et}_{3} \mathrm{~N} \cdot 3 \mathrm{HF}$ and the resulting fully deprotected RNA oligomers $\mathbf{C}$ and $\mathbf{D}$ (Figure 2) were precipitated from ethanol, purified by anion exchange and RP-HPLC, and characterized by MALDI-TOF mass spectrometry. The MS-data confirmed the identity of the synthesized oligomers. Then, the oligomers $\mathbf{a}, \mathbf{b}, \mathbf{C}$, and D were combined to form siRNAs 1-4 (Table 1) following the annealing procedure as described above. 


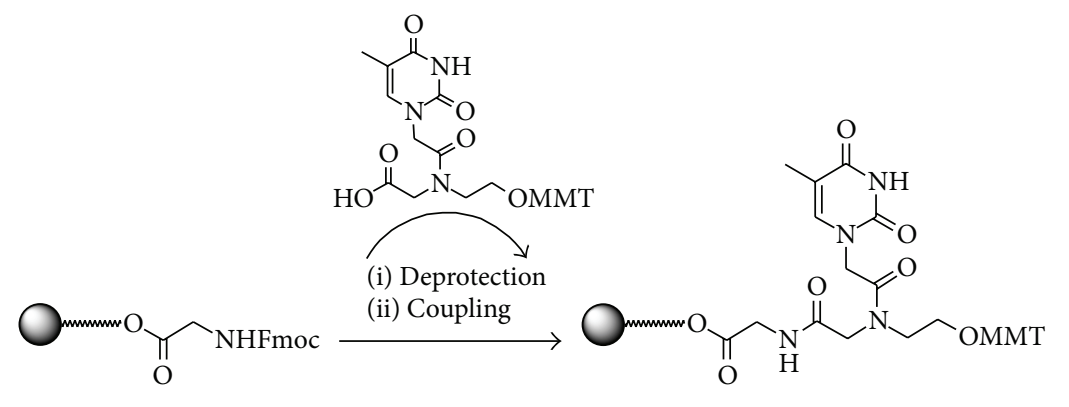

III<smiles>CCNC(=O)C(COO)(COP(=O)(O)OCCN(CC(=O)NCC(=O)O)C(=O)Cn1cc(C)c(=O)[nH]c1=O)C(=O)NC</smiles>

VI
IV

(iii) Deprotection

(iv) CPR phosphorylation

(v) Oxidation

FIGURE 3: Solid phase synthesis of the derivative VI. Reagents and conditions: (i) 20\% Piperidine in DMF; (ii) $0.2 \mathrm{M} \mathrm{HATU}$ in DMF, $0.2 \mathrm{M}$ DIPEA, 0.3 M Lutidine in DMF; (iii) 2\% DCA in DCM; (iv) $0.1 \mathrm{M} \mathrm{CPR} \mathrm{in} \mathrm{ACN,} \mathrm{0.3} \mathrm{M} \mathrm{BTT} \mathrm{in} \mathrm{ACN;} \mathrm{(v)} \mathrm{I}_{2} / \mathrm{H}_{2} \mathrm{O} /$ pyridine.

3.1.2. Synthesis of Modified siRNAs 8-10: Solid Phase Chemical Phosphorylation. Chemical phosphorylation of the $5^{\prime}$-terminus of oligonucleotides is routinely achieved, with high yields using the CPR ([3-(4,4'-Dimetoxytrityloxy)2,2-(N-methylamidocarbonyl)]-propyl-[(cyanoethyl)-(N,Ndiisopropyl)] phosphoramidite) [36]. This method requires CPR introduced by coupling with phosphoramidite method. Aside from its inherent convenience, CPR also has the advantage over enzymatic methods in allowing immediate determination of the phosphorylation efficiency due to the presence of the DMT protecting group. The synthesis of the RNA-5'-PNA-O-phosphate G-H required a previous phase to study and optimize the chemical phosphorylation of hegPNA on solid phase. For this purpose, the chemical phosphorylation of hegPNA monomer was tested on CPG$\mathrm{OH}$ support. The solid supports were functionalized with a Fmoc-Gly-OH as spacer using PyBop/HOBT as activating agents. The yield of glycine introduction, evaluated by spectrophotometric measurements of fluorene derivative, was $0.035 \mathrm{meq} / \mathrm{g}$. CPG-Gly derivatized support was therefore functionalized with the MMT protected hegPNA monomer by PNA coupling procedure (HATU/DIPEA in DMF). After MMT removal, the $\mathrm{OH}$ function was chemically phosphorylated by using commercially available CPR. The CPG support gave good results in the phosphorylation reaction. In fact, the yields of phosphorylation on CPG support resulted $99 \%$ as calculated by the spectrophotometric measurements of DMT cation released after deprotection of phosphate in DCA/DCM. After basic treatment for deprotection and detachment from support, PNA-Ophosphate derivative VI (Figure 3) was purified by RP-C18 cartridge and characterized by ${ }^{31} \mathrm{P}$ NMR and ESI-MS. On the basis of these results, CPG support was chosen to synthesize RNA-5'-PNA-O-phosphate G-H (Figure 2). The identity of full-length oligomers was confirmed by MALDI-TOF analysis. The oligomers $\mathbf{a}, \mathbf{b}, \mathbf{G}$, and $\mathbf{H}$ (Figure 2) were combined to form siRNAs 8-10 (Table 1) following the annealing procedure as described above.

3.1.3. Synthesis of Modified siRNAs 5-7, 11-13, and 17-19. Modified $3^{\prime}, 5^{\prime}$-PNA siRNAs were synthesized in order to study the effect of PNA on both $5^{\prime}$ and $3^{\prime}$ ends of siRNAs sense and antisense strands. The support VIII (Figure 4) was synthesized starting from CPG-OH support VII by reaction with Fmoc-amino and MMT-hydroxyethylglycine PNAs following procedures reported elsewhere [27]. After deprotection of $\mathrm{OH}$ function, the synthesis of RNA tract was performed using commercially available $2^{\prime}$-O-TBDMS$3^{\prime}$-O-phosphoramidite ribonucleotides on oligo synthesizer affording oligomers $\mathbf{O}-\mathbf{P}$ (Table 1). To obtain the oligomers E-F and I-L (Table 1), the last couplings were done with $5^{\prime}$ MMT-NH-thymidine-3'-O-phosphoramidite and MMT-OPNA monomer as described for C-D and G-H. Deprotection and cleavage of oligomers from support were carried out as described above. HPLC purification and MS-data confirmed 


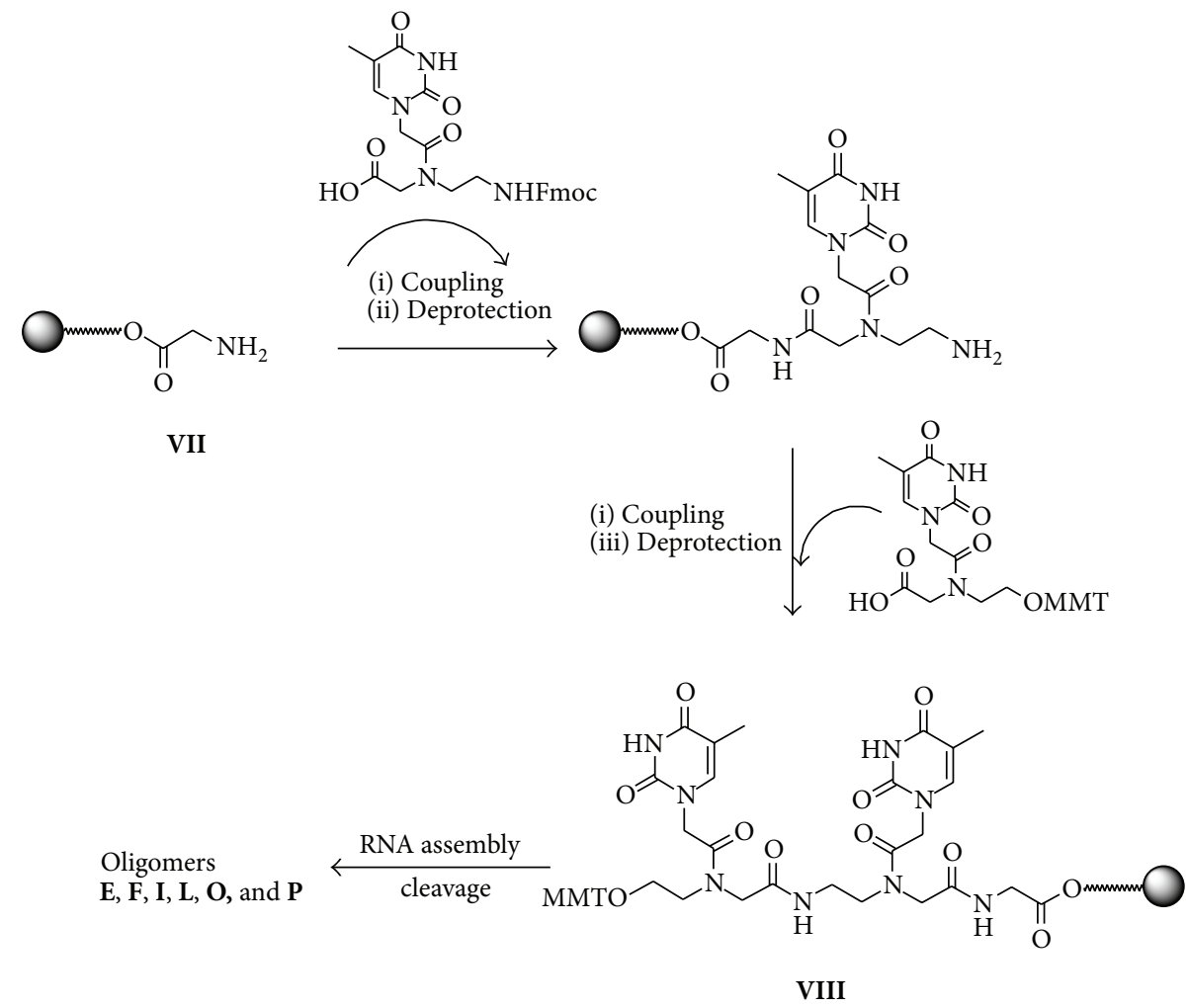

FIgURE 4: Synthesis of the support VIII. Reagents and conditions: (i) 0.2 M HATU in DIPEA/DMF; (ii) 20\% Piperidine in DMF; (iii) 3\%; DCA in DCM.<smiles>[X]CCN(CCOP(OCCN(CC(=O)OC)C(=O)Cn1cc(C)c(=O)[nH]c1=O)N(C(C)C)C(C)C)C(=O)Cn1cc(C)c(=O)[nH]c1=O</smiles>

FIGURE 5: Synthesis of phosphoramidite PNA building block X.

the identities of chimeras E-F, I-L, and O-P. The siRNAs 57, 11-13, and 17-19 were assembled as described in Table 1 following the annealing procedure as described above.

3.1.4. Synthesis of the siRNAs 14-16. We synthesized a new set of siRNAs bearing at $5^{\prime}$ end a PNA monomer linked by phosphodiester bridge and having the C-terminus as methylamide cap. For this purpose, phosphoramidite PNA building block $\mathbf{X}$ (Figure 5) was prepared by reaction of methyl ester derivative of hegPNA IX with 2cianoethyl-N,N-diisopropylchlorophosphoramidite in dry DIPEA/DCM. After LC purification and ${ }^{31} \mathrm{P}$ NMR characterization, the PNA phosphoramidite derivative $\mathbf{X}$ was used as last coupling monomer to obtain the precursor of the oligomers M-N.

Methylamine treatment (33\% in absolute ethanol) accomplished the deprotection and detachment of the oligomers from the support as methylamide derivatives. Desilylation gave the RNA-5'-O-PNA-CONHCH 3 oligomers $\mathbf{M}$ $\mathbf{N}$ (Table 1) that after purification and characterization by MALDI-TOF MS were combined with $\mathbf{a}-\mathbf{b}$ to give the siRNAs 14-16 (Table 1) following the annealing procedure as described above.

3.2. Circular Dichroism Characterization of Native and Modified siRNAs. Although the conformational features alone do not warrant an interfering activity, a double-helical RNAlike A conformation is required for effective gene silencing. Indeed, the modified siRNAs 2-19 were all found to retain an RNA-like A conformation exhibiting CD spectra similar to those of the unmodified siRNA 1 with a typical positive shoulder at $280 \mathrm{~nm}$ and a large positive band at $260 \mathrm{~nm}$. This behavior suggested that terminal amide linkages at $3^{\prime}$ 


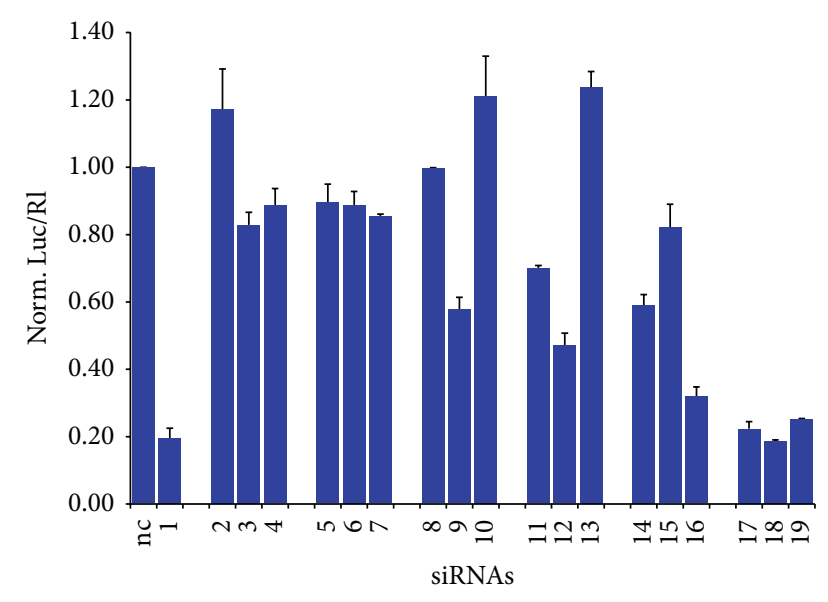

FIGURE 6: RNAi activity of native and modified siRNAs toward luciferase gene expression in HeLa cells. Small interfering RNAs were transfected at $10 \mathrm{nM}$ concentration and luciferase activities were determined after $48 \mathrm{~h}$. The firefly luciferase activity (Luc) was then normalized to that of Renilla luciferase (Rl) and the uninhibited activity of cells transfected with an unrelated siRNA (nc) was set to 1. Data are the mean \pm s.d. from at least three experiments.

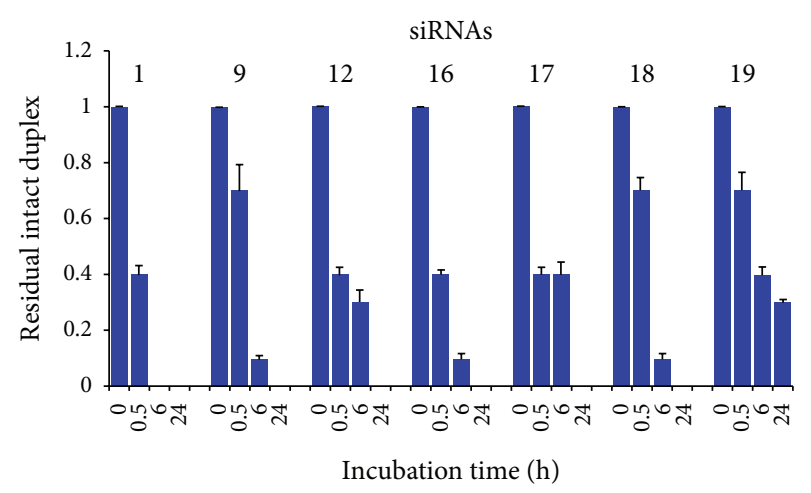

FIGURE 7: Stability of natural and modified siRNAs in $100 \%$ fetal bovine serum at $37^{\circ} \mathrm{C}$. After incubation, siRNAs were analyzed by PAGE and ethidium bromide staining. Gel images were captured by ChemiDoc XRS (Bio-Rad) and RNA bands were quantified by Image Lab software (Bio-Rad). Signal intensity values at $t_{0}$ were set at 1 .

and/or $5^{\prime}$ ends do not interfere with the typical A conformation of dsRNA. Thermal stability of the siRNAs 2-19 was also considered by thermal denaturation $\mathrm{CD}$ experiments highlighting a general thermodynamic destabilization for all modified duplexes. In fact, melting temperatures lower than that of siRNA $1\left(76^{\circ} \mathrm{C}\right)$ were recorded in all cases suggesting that the presence of the terminal amide linkages caused a limited destabilization of the secondary structure, as inferred from CD-melting values (Table 1).

3.3. Compatibility of Modified siRNAs with the RNAi Machinery. To verify the compatibility of modified siRNAs containing amide linkages with the cellular RNAi machinery, siRNAs 2-19 were evaluated for their ability to specifically inhibit firefly luciferase gene expression in cultured HeLa cells.
siRNA duplexes were cotransfected with the reporter plasmid combination pGL2/phRL-TK using cationic liposomes. pGL2 is transcribed into the Photinus pyralis luciferase mRNA, targeted by the siRNA, whereas phRL-TK encodes the Renilla reniformis luciferase, used as control to normalize the data with the efficiency of transfection. As shown in Figure 6, the native siRNA 1 effectively and selectively reduced firefly luciferase activity by more than $80 \%$ compared to an unrelated siRNA (nc).

We then confirmed that the introduction of PNA modification at the $3^{\prime}$ end in either or both strands does not show any loss of interfering effect, because all the modified duplexes (siRNAs 17-19) were as efficient as the siRNA 1. On the other hand, the presence of the amide linkage dramatically decreased the interference activity when it was located at $5^{\prime}$ and at both $3^{\prime}, 5^{\prime}$ regions of siRNAs, demonstrating that the modification at $5^{\prime}$ end mostly controls the silencing activity. Interestingly, " 5 '-capped" siRNAs partially restored the interfering effect. Therefore, the siRNA $\mathbf{1 6}$ appeared to be more effective than all the other $5^{\prime}$-modified duplexes, while the siRNA 18 appeared to be more effective than all the other modified duplexes.

3.4. Serum Stability of Modified siRNAs. Improving the biostability is also crucial for therapeutic purposes of synthetic siRNAs. Experiments were planned to test whether the introduction of the amide linkages at $5^{\prime}$ and/or at $3^{\prime}$ ends leads to siRNAs more stable than unmodified ones in the extracellular environment. Therefore, the nuclease resistance of 2-19 was investigated through incubation in $100 \%$ fetal bovine serum (FBS) at $37^{\circ} \mathrm{C}$ using unmodified siRNA 1 as control (Figure 7). At various incubation times, aliquots of each siRNA were analyzed by electrophoresis on $15 \%$ polyacrylamide gels to detect any degradation products. The unmodified siRNA 1 was greatly degraded within $30 \mathrm{~min}$ (Figure 7) as well as almost all siRNAs featuring only one modified strand (data not shown), except for $\mathbf{9}$ and $\mathbf{1 2}$ that exhibited significant amounts of intact duplex at $6 \mathrm{~h}$ of incubation. Similar results were obtained with siRNAs 16-18. Finally, the introduction of PNA on both strands markedly increased the resistance to serum-derived nucleases as demonstrated by $\mathbf{1 9}$ that showed still evident intact duplex even after $24 \mathrm{~h}$ of incubation.

3.5. Molecular Docking Simulations. Molecular docking simulations were attained in order to provide a putative model of the interaction of the newly identified siRNAs with the human Argonaute 2 (hAgo 2) protein at atomistic level. In particular, the software AutoDock4.2 (AD4) [37, 38] was employed to dock the ASs of the siRNAs bearing the most performing modifications at the $3^{\prime}$ and $5^{\prime}$ ends. In particular, the chimeric $3^{\prime}$-OH-PNA AS of siRNA 17 (oligomer O) and the AS of " 5 -capped" siRNA 16 (oligomer M)" were docked in the recently published structure of hAgo 2 in complex with miR-20a (PDB code 4F3T) [9]. The modified siRNA ASs were constructed starting from the RNA cocrystal conformation where each nucleotide was mutated to obtain the target sequence, while at the $3^{\prime}$ and $5^{\prime}$ terminals the proper 


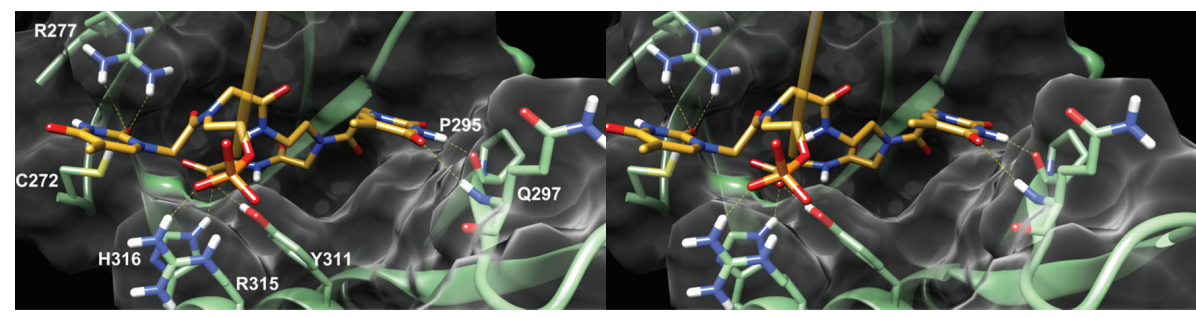

FIGURE 8: Stereoview of the predicted binding mode of the $3^{\prime}-\mathrm{OH}-\mathrm{PNA}$ AS of siRNA 17 in the hAgo 2 X-ray structure. For clarity reasons, the PNA structure is depicted (yellow sticks) while the RNA backbone is shown as an orange transparent ribbon. The protein is depicted as green sticks (interacting residues) and ribbons and white transparent surface. H-bonds are indicated as yellow dashed lined.

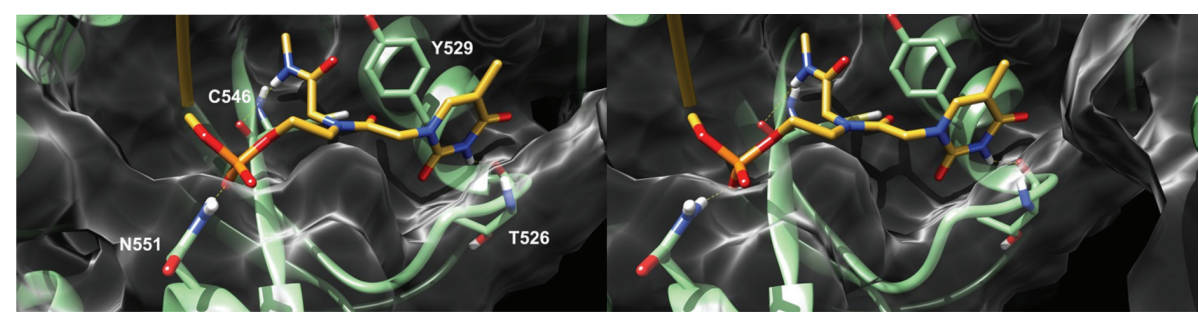

FIGURE 9: Stereoview of the predicted binding mode of the " 5 ' -capped" AS of siRNA 16 in the hAgo 2 X-ray structure. For clarity reasons, only the PNA structure is depicted (yellow sticks) while the RNA backbone is shown as an orange transparent ribbon. The protein is depicted as green sticks (interacting residues) and ribbons and white transparent surface. H-bonds are indicated as yellow dashed lined.

modifications were attained. These latter groups were free to move during the docking simulations. For both docking calculations only the lowest energy conformations $\left(\Delta \mathrm{G}_{\mathrm{AD} 4}\right)$ were considered and analyzed.

In the theoretical complex between the AS of siRNA 17 and hAgo 2 the modified RNA adopted a conformation similar to that of the cocrystal RNA with the $3^{\prime}$ end contacting the protein PAZ domain. In this position, the terminal PNA residues are embedded in a wide gorge of the aforementioned protein region establishing several favorable interactions (Figure 8). In particular the phosphate group linking the PNA structure to the RNA one is forming an ionic interaction with $\mathrm{R} 315$ while the heg residue is able to project the attached thymine base to form two H-bonds with R277 and C272. On the other hand, the second thymine base is pointing towards the opposite site of the gorge H-bonding with P295 and Q297 backbone CO and NH, respectively. Finally, the terminal carboxylate group is able to H-bond H316 and Y311 side-chains.

A well-defined binding pose was also found for the " 5 ' capped" AS of siRNA 16 where the terminal $5^{\prime}$ is pointing towards the hAgo 2 middomain (Figure 9). In this position the phosphate group is H-bonding N551 with the thymine moiety being optimally oriented to establish a $\pi-\pi$ interaction with Y529 and an H-bond with T526 backbone CO. Moreover, the terminal methylamide cap can form an additional $\mathrm{H}$-bond interaction with $\mathrm{C} 546$ backbone CO.

\section{Discussion}

A rational design of effective chemically modified siRNAs must consider the $3^{\prime}$ and $5^{\prime}$ termini of siRNAs as critical determinants for the silencing activity because these regions interact with the binding domains of hAgo 2, that is, the signature component of the RNAi machinery. In particular, the selective loading of the guide strand into RISC is essential for avoiding undesirable side effects, while the release of the $3^{\prime}$ end from the PAZ domain during the cleavage of the mRNA is crucial to perform RNase activity [40]. In this respect, experiments on cell cultures have demonstrated that chemical modifications of siRNAs at $3^{\prime}$ end modulate the silencing activity, increase the nuclease resistance, and influence the affinity of the $3^{\prime}$-overhang portion for PAZ [41-44]. Instead, the phosphorylation of the $5^{\prime}$ end of siRNA is one of the first steps required for antisense strand selection and for its function in RISC $[45,46]$. The $5^{\prime}$ end of siRNA is tethered to hAgo 2 through a multitude of interactions to form a very tight binding pocket composed of residues mostly from the middomain and capped on one side by PIWI domain residues [47-50]. All three nonbridging oxygen atoms of the $5^{\prime}$ phosphate interact with several protein side chains and it has been suggested that the proper interactions between the $5^{\prime}$-phosphate and hAgo 2 define the position of the RNA guide with respect to the active site to ensure that cleavage of targets occurs at a well-defined and predictable position. In addition, early work on siRNA chemical modifications suggested the importance of the thermal stability of the siRNA duplex, as measured by the melting temperature, $\mathrm{Tm}$, on the gene silencing activity [51-53]. However, there is no obvious correlation between the overall duplex Tm and the gene silencing activity of the siRNA. Rather, specific regions of the siRNA duplex have distinct tolerances toward stabilization and destabilization, resulting in positionspecific changes of activity upon incorporation of chemical 
modifications that affect thermal stability [54]. Therefore, the thermodynamic properties of siRNA molecules play a central role in determining the molecule's functionality by facilitating several steps, namely, duplex unwinding, correct strand selection, reduced unspecific recognition of target, and mRNA turnover.

SiRNAs 2-7, bearing hegPNA at $5^{\prime}$ end of sense and antisense strands, did not exhibit any mRNA degradation activity and it might be postulated that in these siRNAs the hegPNA inhibits phosphorylation event at the $5^{\prime}$ terminus. Thus, the absence of the phosphate at $5^{\prime}$ end of guide strand in the siRNAs $\mathbf{2}$ and $\mathbf{5}$ could result in a loss of specificity and efficiency of target cleavage because the RNA guide might adopt incorrect positions in the RNA binding groove of hAgo 2. This is similar to previously published results [55] where unlocked nucleic acid (UNA) modification at positions 1 and 2 of $5^{\prime}$-terminus prevented phosphorylation by Clpl kinase abrogating interaction with hAgo 2. Furthermore, it is also reasonable that in siRNAs 2 and 5, the amide-bond linkage placed in substitution of the phosphodiester bridge between the nucleotides 1 and 2 of the $5^{\prime}$ region might derange the required interactions between the AS strand and hAgo 2. Modifying siRNAs by introducing hegPNA monomer at the $5^{\prime}$-terminus of the sense strand (siRNAs 3 and 6) resulted in a loss of silencing activity. This unexpected result could be explained by the presence of a thermal destabilization due to the structural complexity induced by the PNA in the siRNAs $\mathbf{3}$ and $\mathbf{6}$, as confirmed by thermal denaturation studies (Table 1). In this respect, the thermal destabilization would translate in the SS selection by RISC rather the AS and this is consistent with the asymmetry rule of siRNAs. This hypothesis is also confirmed by the observed behavior of siRNAs 4 and 7 where the introduction of PNA at $5^{\prime}$ end of both strands resulted again in a loss of silencing activity. Noteworthy, the presence of PNA also at $3^{\prime}$ end (siRNAs 57) had no improvement on the silencing activity, although the analysis of data resulting from silencing activity of the siRNAs 17-19 showed that the PNA units into $3^{\prime}$-dangling region were well tolerated by RNAi machinery. In particular, the modification of the sense strand of siRNA 18 resulted in an increased silencing activity probably by inducing the correct loading of antisense strand by RISC. In this respect, the theoretical model of the complex between the AS of $\mathbf{1 7}$ and the PAZ domain of hAgo 2 would indicate that, in this siRNA, the $3^{\prime}$-OH-PNA is able to establish several and tight interactions with the protein counterpart and thus positively modulating the rates of dislodging and lodging of the AS in and from the PAZ domain and providing, in turn, a further determining factor for its efficiency and potency.

In order to assess the impact of the chemical phosphorylation of hegPNA at $5^{\prime}$ end on the interfering activity, siRNAs 8-13 were synthesized. As shown in Figure 5, siRNAs 8 and 11 containing a PNA-phosphate at the $5^{\prime}$ end of antisense strand were less potent than unmodified siRNA, reproducing the same results obtained for siRNAs $\mathbf{2}$ and $\mathbf{5}$. In addition to the lack of the proper AS/hAgo 2 interactions ascribable to the presence of the internucleotidic amide-bond linkage, the low silencing potential may be also caused by the $5^{\prime}$-terminal phosphate instability. In principle, the $5^{\prime}$-phosphate could be removed in the cellular environment and the $5^{\prime}$ terminal heg PNA could not be rephosphorylated by cellular kinase Clp1 as already suggested from the behavior of the siRNAs 2-7. Furthermore, siRNAs $\mathbf{9}$ and $\mathbf{1 2}$ resulted in being significantly more active than siRNAs $\mathbf{8}$ and 11. The only partial restoring of the silencing activity of $\mathbf{9}$ and $\mathbf{1 2}$ may be rationalized considering that both the modified SS (no silencing) and the unmodified AS (silencing) occur.

Finally, we synthesized novel modified siRNAs bearing an hegPNA monomer inserted at $5^{\prime}$ end of RNA domain by phosphodiester linkage and having at the C-terminus a methylamide function (siRNA 14-16, Table 1). Interestingly, improved silencing performances were observed for siRNAs 14 and 16 in whichwe supposethat the modified ASis selectively loaded on RISC due to the thermal asymmetry conferred by methylamide PNA at $5^{\prime}$ end. In fact, siRNA 15 was not effective, probably, since the modified sense strand is preferentially selected. The " 5 '-capped" siRNAs $\mathbf{1 4}$ and $\mathbf{1 6}$ partially restored an interfering effect besides methylamide cap blocks the siRNA versus phosphorylation [56-61]. Also, the specific interaction detected between the methylamide and the hAgo 2 middomain would further substantiate a role of the chemical modification in the selective loading of the AS by the protein. Furthermore, it is worth mentioning that the presence of phosphodiester linkage between residues 1 and 2 in the $5^{\prime}$ region of the siRNAs $\mathbf{1 4}$ and $\mathbf{1 6}$ seems to have an additional role in maintaining the correct binding to direct mRNA degradation.

\section{Conclusions}

In summary, we reported the synthesis of modified siRNAs containing terminal amide linkages by introducing hegPNA moieties at $5^{\prime}, 3^{\prime}$, and at both termini. It was revealed that modified siRNAs are only compatible with the RNAi machinery when amide bonds are introduced at $3^{\prime}$ end of the siRNAs. In particular, poor efficacy was observed when hegPNA or hegPNA phosphate moieties are placed at $5^{\prime}$ ends because this region plays a crucial role in maintaining the correct binding to address the mRNA-target degradation. Further, " 5 '-capped" siRNAs partially restored the interfering activity maybe favoring the AS selective loading as well as the correct binding of the AS by the protein. Besides, we examined the biostability of the modified siRNAs and showed the introduction of amide linkages on both strands of siRNAs markedly increased the resistance to serum-derived nucleases. Molecular docking simulations were attained to give at atomistic level a clearer picture of the effect of the most interesting modifications on the interactions with the human Argonaute 2 PAZ, MID, and PIWI domains. In conclusion, this report appends further on the understanding of the effects of chemical modifications and of their location in siRNA structure on the silencing properties and sensitivity to the degradation by ribonucleases and thus opens to the future possibility to exploit these chemical modifications in studying new structure-function relationships. 
The following abbreviations are used throughout the test.

$\begin{array}{ll}\text { Abbreviations } \\ \text { BTT: } & \text { 5-Benzylthio-1H-tetrazole } \\ \text { CD: } & \text { Circular dichroism } \\ \text { CPG: } & \text { Controlled pore glass } \\ \text { CPR: } & \text { Chemical phosphorylation reagent } \\ \text { DCM: } & \text { Dichloromethane } \\ \text { DCA: } & \text { dichloroacetic acid } \\ \text { DEPC: } & \text { Diethylpirocarbonate } \\ \text { DMF: } & \text { N,N-Dimethylformamide } \\ \text { DMT: } & \text { Dimethoxytrityl [bis(4-methoxyphenyl) } \\ & \text { (phenyl)methyl] } \\ \text { ESI: } & \text { Electrospray ionization } \\ \text { FBS: } & \text { Fetal bovine serum } \\ \text { Fmoc: } & \text { 9-Fluorenylmethoxycarbonyl } \\ \text { HOBT: } & \text { N-Hydroxybenzotriazole } \\ \text { HPLC: } & \text { High performance liquid chromatography } \\ \text { MALDI-TOF: } & \text { Matrix assisted laser desorption } \\ & \text { ionization-time of flight } \\ \text { PyBOP: } & \text { (Benzotriazol-1-yloxy) } \\ & \text { tripyrrolidinophosphonium } \\ \text { RNAi: } & \text { hexafluorophosphate } \\ \text { RISC: } & \text { RNA interference } \\ \text { RNase: } & \text { RNA-induced silencing complex } \\ \text { RP-HPLC: } & \text { Ribonuclease } \\ \text { siRNA: } & \text { Reverse phase HPLC } \\ \text { TBDMS: } & \text { Small interfering RNA } \\ \text { Tm: } & \text { Melting temperature. } \\ & \end{array}$

\section{Conflict of Interests}

The authors declare that there is no conflict of interests regarding the publication of this paper.

\section{Acknowledgments}

This work was supported by grants from MIUR (PRIN 2009).

\section{References}

[1] A. Fire, S. Xu, M. K. Montgomery, S. A. Kostas, S. E. Driver, and C. C. Mello, "Potent and specific genetic interference by doublestranded RNA in caenorhabditis elegans," Nature, vol. 391, no. 6669, pp. 806-811, 1998.

[2] S. M. Elbashir, J. Harborth, W. Lendeckel, A. Yalcin, K. Weber, and T. Tuschl, "Duplexes of 21-nucleotide RNAs mediate RNA interference in cultured mammalian cells," Nature, vol. 411, no. 6836, pp. 494-498, 2001.

[3] N. J. Caplen, S. Parrish, F. Imani, A. Fire, and R. A. Morgan, "Specific inhibition of gene expression by small doublestranded RNAs in invertebrate and vertebrate systems," Proceedings of the National Academy of Sciences of the United States of America, vol. 98, no. 17, pp. 9742-9747, 2001.

[4] N. C. Lau, L. P. Lim, E. G. Weinstein, and D. P. Bartel, "An abundant class of tiny RNAs with probable regulatory roles in
Caenorhabditis elegans,' Science, vol. 294, no. 5543, pp. 858862, 2001.

[5] S. Weitzer and J. Martinez, "The human RNA kinase hClp1 is active on $3^{\prime}$ transfer RNA exons and short interfering RNAs," Nature, vol. 447, no. 7141, pp. 222-226, 2007.

[6] D. S. Schwarz, G. Hutvágner, T. Du, Z. Xu, N. Aronin, and P. D. Zamore, "Asymmetry in the assembly of the RNAi enzyme complex," Cell, vol. 115, no. 2, pp. 199-208, 2003.

[7] P. J. F. Leuschner, S. L. Ameres, S. Kueng, and J. Martinez, "Cleavage of the siRNA passenger strand during RISC assembly in human cells," EMBO Reports, vol. 7, no. 3, pp. 314-320, 2006.

[8] J.-B. Ma, K. Ye, and D. J. Patel, "Structural basis for overhangspecific small interfering RNA recognition by the PAZ domain," Nature, vol. 429, no. 6989, pp. 318-322, 2004.

[9] E. Elkayam, C. D. Kuhn, A. Tocilj et al., "The structure of human argonaute-2 in complex with miR-20a," Cell, vol. 150, no. 1, pp. 100-110, 2012.

[10] V. Ambros, “The functions of animal microRNAs," Nature, vol. 431, no. 7006, pp. 350-355, 2004.

[11] B. Berkhout and K.-T. Jeang, "MicroRNAs in viral gene regulation," Biochimica et Biophysica Acta. Gene Regulatory Mechanisms, vol. 1809, no. 11-12, p. 587, 2011.

[12] A. Russo and N. Potenza, "Antiviral effects of human microRNAs and conservation of their target sites," FEBS Letters, vol. 585, no. 16, pp. 2551-2555, 2011.

[13] D. R. Corey, "Chemical modification: the key to clinical application of RNA interference?" Journal of Clinical Investigation, vol. 117, no. 12, pp. 3615-3622, 2007.

[14] S. T. Crooke, "Progress in antisense technology," Annual Review of Medicine, vol. 55, pp. 61-95, 2004.

[15] M. Gaglione and A. Messere, "Recent progress in chemically modified siRNAs," Mini Reviews in Medicinal Chemistry, vol. 10, no. 7, pp. 578-595, 2010.

[16] A. Lingel, B. Simon, E. Izaurralde, and M. Sattler, "Nucleic acid $3^{\prime}$-end recognition by the Argonaute2 PAZ domain," Nature Structural and Molecular Biology, vol. 11, no. 6, pp. 576-577, 2004.

[17] S. Shah and S. H. Friedman, "Tolerance of RNA interference toward modifications of the $5^{\prime}$ antisense phosphate of small interfering RNA," Oligonucleotides, vol. 17, no. 1, pp. 35-43, 2007.

[18] J.-B. Ma, Y.-R. Yuan, G. Meister, Y. Pei, T. Tuschl, and D. J. Patel, "Structural basis for $5^{\prime}$-end-specific recognition of guide RNA by the A. fulgidus Piwi protein," Nature, vol. 434, no. 7033, pp. 666-670, 2005.

[19] M. Egholm, P. E. Nielsen, O. Buchardt, and R. H. Berg, "Recognition of guanine and adenine in DNA by cytosine and thymine containing peptide nucleic acids (PNA)," Journal of the American Chemical Society, vol. 114, no. 24, pp. 9677-9678, 1992.

[20] B. Hyrup and P. E. Nielsen, "Peptide nucleic acids (PNA): synthesis, properties and potential applications," Bioorganic and Medicinal Chemistry, vol. 4, no. 1, pp. 5-23, 1996.

[21] M. Komiyama, S. Ye, X. Liang et al., "PNA for one-base differentiating protection of DNA from nuclease and its use for SNPs detection," Journal of the American Chemical Society, vol. 125, no. 13, pp. 3758-3762, 2003.

[22] E. Uhlmann, A. Peyman, G. Breipohl, and D. W. Will, "PNA: Synthetic polyamide nucleic acids with unusual binding properties," Angewandte Chemie. International Edition, vol. 37, no. 20, pp. 2797-2823, 1998.

[23] E. Uhlmann, "Peptide nucleic acids (PNA) and PNA-DNA chimeras: from high binding affinity towards biological function," Biological Chemistry, vol. 379, no. 8-9, pp. 1045-1052, 1998. 
[24] D. Capasso, L. de Napoli, G. di Fabio et al., "Solid phase synthesis of DNA-3' -PNA chimeras by using Bhoc/Fmoc PNA monomers," Tetrahedron, vol. 57, no. 46, pp. 9481-9486, 2001.

[25] V. Esposito, A. Randazzo, A. Messere et al., "Synthesis and structural characterization of PNA-DNA quadruplex-forming chimeras," European Journal of Organic Chemistry, no. 17, pp. 3364-3371, 2003.

[26] L. Petraccone, E. Erra, A. Messere et al., "Targeting duplex DNA with DNA-PNA chimeras? Physico-chemical characterisation of a triplex DNA-PNA/DNA/DNA," Biopolymers, vol. 73, no. 4, pp. 434-442, 2004.

[27] N. Potenza, L. Moggio, G. Milano et al., "RNA interference in mammalia cells by RNA-3'-PNA chimeras," International Journal of Molecular Sciences, vol. 9, no. 3, pp. 299-315, 2008.

[28] A. Finotti, M. Borgatti, V. Bezzerri et al., "Effects of decoy molecules targeting NFkappaB transcription factors in cystic fibrosis IB3-1 cells: recruitment of NFkappaB to the IL-8 gene promoter and transcription of the IL-8 gene," Artificial DNA: PNA \& XNA, vol. 2, no. 3, pp. 97-104, 2012.

[29] A. Zannetti, S. del Vecchio, A. Romanelli et al., "Inhibition of Spl activity by a decoy PNA-DNA chimera prevents urokinase receptor expression and migration of breast cancer cells," Biochemical Pharmacology, vol. 70, no. 9, pp. 1277-1287, 2005.

[30] M. Borgatti, A. Romanelli, M. Saviano et al., "Resistance of decoy PNA-DNA chimeras to enzymatic degradation in cellular extracts and serum," Oncology Research, vol. 13, no. 5, pp. 279$287,2002$.

[31] A. Romanelli, C. Pedone, M. Saviano et al., "Molecular interactions between nuclear factor $\kappa \mathrm{B}(\mathrm{NF}-\kappa \mathrm{B})$ transcription factors and a PNA-DNA chimera mimicking NF- $\kappa$ B binding sites," European Journal of Biochemistry, vol. 268, no. 23, pp. 60666075, 2001.

[32] Y.-L. Chiu, A. Ali, C.-Y. Chu, H. Cao, and T. M. Rana, "Visualizing a correlation between siRNA localization, cellular uptake, and RNAi in living cells," Chemistry and Biology, vol. 11, no. 8, pp. 1165-1175, 2004.

[33] W. Gong and J. P. Desaulniers, "Gene-silencing properties of siRNAs that contain internal amide-bond linkages," Bioorganic \& Medicinal Chemistry Letters, vol. 22, no. 22, pp. 6934-6937, 2012.

[34] J. J. Turner, S. Jones, M. M. Fabani, G. Ivanova, A. A. Arzumanov, and M. J. Gait, "RNA targeting with peptide conjugates of oligonucleotides, siRNA and PNA," Blood Cells, Molecules, and Diseases, vol. 38, no. 1, pp. 1-7, 2007.

[35] G. Breipohl, D. W. Will, A. Peyman, and E. Uhlmann, "Novel synthetic routes to PNA monomers and PNA-DNA linker molecules," Tetrahedron, vol. 53, no. 43, pp. 14671-14686, 1997.

[36] A. Guzaev, H. Salo, A. Azhayev, and H. Lonnberg, "A new approach for chemical phosphorylation of oligonucleotides at the $5^{\prime}$-terminus," Tetrahedron, vol. 51, no. 34, pp. 9375-9384, 1995.

[37] R. Huey, G. M. Morris, A. J. Olson, and D. S. Goodsell, "A semiempirical free energy force field with charge-based desolvation," Journal of Computational Chemistry, vol. 28, no. 6, pp. 1145-1152, 2007.

[38] S. Cosconati, S. Forli, A. L. Perryman, R. Harris, D. S. Goodsell, and A. J. Olson, "Virtual screening with AutoDock: theory and practice," Expert Opinion on Drug Discovery, vol. 5, no. 6, pp. 597-607, 2010.

[39] E. F. Pettersen, T. D. Goddard, C. C. Huang et al., "UCSF Chimera-a visualization system for exploratory research and analysis," Journal of Computational Chemistry, vol. 25, no. 13, pp. 1605-1612, 2004.

[40] M. Sano, M. Sierant, M. Miyagishi, M. Nakanishi, Y. Takagi, and S. Sutou, "Effect of asymmetric terminal structures of short RNA duplexes on the RNA interference activity and strand selection," Nucleic Acids Research, vol. 36, no. 18, pp. 5812-5821, 2008.

[41] Y. Ueno, Y. Watanabe, A. Shibata et al., "Synthesis of nucleaseresistant siRNAs possessing universal overhangs," Bioorganic and Medicinal Chemistry, vol. 17, no. 5, pp. 1974-1981, 2009.

[42] Á. Somoza, M. Terrazas, and R. Eritja, "Modified siRNAs for the study of the PAZ domain," Chemical Communications, vol. 46, no. 24, pp. 4270-4272, 2010.

[43] K. Yoshikawa, A. Ogata, C. Matsuda et al., "Incorporation of biaryl units into the $5^{\prime}$ and $3^{\prime}$ ends of sense and antisense strands of siRNA duplexes improves strand selectivity and nuclease resistance," Bioconjugate Chemistry, vol. 22, no. 1, pp. 42-49, 2011.

[44] M. Gaglione, N. Potenza, G. di Fabio et al., "Tuning RNA interference by enhancing siRNA/PAZ recognition," ACS Medicinal Chemistry Letters, vol. 4, pp. 75-78, 2013.

[45] A. Boutla, C. Delidakis, I. Livadaras, M. Tsagris, and M. Tabler, "Short 5 '-phosphorylated double-stranded RNAs induce RNA interference in Drosophila," Current Biology, vol. 11, no. 22, pp. 1776-1780, 2001.

[46] D. S. Schwarz, G. Hutvágner, B. Haley, and P. D. Zamore, "Evidence that siRNAs function as guides, not primers, in the Drosophila and human RNAi pathways," Molecular Cell, vol. 10, no. 3, pp. 537-548, 2002.

[47] A. Boland, F. Tritschler, S. Heimstädt, E. Izaurralde, and O. Weichenrieder, "Crystal structure and ligand binding of the MID domain of a eukaryotic Argonaute protein," EMBO Reports, vol. 11, no. 7, pp. 522-527, 2010.

[48] A. Boland, E. Huntzinger, S. Schmidt, E. Izaurralde, and O. Weichenrieder, "Crystal structure of the MID-PIWI lobe of a eukaryotic argonaute protein," Proceedings of the National Academy of Sciences of the United States of America, vol. 108, no. 26, pp. 10466-10471, 2011.

[49] F. Frank, N. Sonenberg, and B. Nagar, "Structural basis for $5^{\prime}$ nucleotide base-specific recognition of guide RNA by human AGO2," Nature, vol. 465, no. 7299, pp. 818-822, 2010.

[50] J. S. Parker, S. M. Roe, and D. Barford, "Structural insights into mRNA recognition from a PIWI domain-siRNA guide complex," Nature, vol. 434, no. 7033, pp. 663-666, 2005.

[51] Y.-L. Chiu and T. M. Rana, "siRNA function in RNAi: a chemical modification analysis," RNA, vol. 9, no. 9, pp. 1034-1048, 2003.

[52] T. P. Prakash, C. R. Allerson, P. Dande et al., "Positional effect of chemical modifications on short interference RNA activity in mammalian cells," Journal of Medicinal Chemistry, vol. 48, no. 13, pp. 4247-4253, 2005.

[53] J. K. Watts, N. Choubdar, K. Sadalapure et al., " 2 '-Fluoro$4^{\prime}$-thioarabino-modified oligonucleotides: conformational switches linked to siRNA activity," Nucleic Acids Research, vol. 35, no. 5, pp. 1441-1451, 2007.

[54] H. Peacock, A. Kannan, P. A. Beal, and C. J. Burrows, "Chemical modification of siRNA bases to probe and enhance RNA interference," Journal of Organic Chemistry, vol. 76, no. 18, pp. 7295-7300, 2011.

[55] D. M. Kenski, A. J. Cooper, J. J. Li et al., "Analysis of acyclic nucleoside modifications in siRNAs finds sensitivity at position 1 that is restored by $5^{\prime}$-terminal phosphorylation both in vitro 
and in vivo," Nucleic Acids Research, vol. 38, no. 2, pp. 660-671, 2009.

[56] Q. Xu, D. Katkevica, and E. Rozners, "Toward amide-modified RNA: synthesis of $3^{\prime}$-aminomethyl-5' - carboxy-3', $5^{\prime}$-dideoxy nucleosides," Journal of Organic Chemistry, vol. 71, no. 16, pp. 5906-5913, 2006.

[57] D. R. Corey, "RNA learns from antisense," Nature Chemical Biology, vol. 3, no. 1, pp. 8-11, 2007.

[58] W. Gong and J.-P. Desaulniers, "Synthesis and properties of rnas that contain a PNA-RNA dimer," Nucleosides, Nucleotides and Nucleic Acids, vol. 31, no. 5, pp. 389-400, 2012.

[59] C. Selvam, S. Thomas, J. Abbott, S. D. Kennedy, and E. Rozners, "Amides as excellent mimics of phosphate linkages in RNA," Angewandte Chemie. International Edition, vol. 50, no. 9, pp. 2068-2070, 2011.

[60] P. S. Pallan, P. von Matt, C. J. Wilds, K.-H. Altmann, and M. Egli, "RNA-binding affinities and crystal structure of oligonucleotides containing five-atom amide-based backbone structures," Biochemistry, vol. 45, no. 26, pp. 8048-8057, 2006.

[61] T. K. Chakraborty, P. K. Gajula, and D. Koley, "Studies directed toward the development of amide-linked RNA mimics: synthesis of the monomeric building blocks," Journal of Organic Chemistry, vol. 73, no. 17, pp. 6916-6919, 2008. 

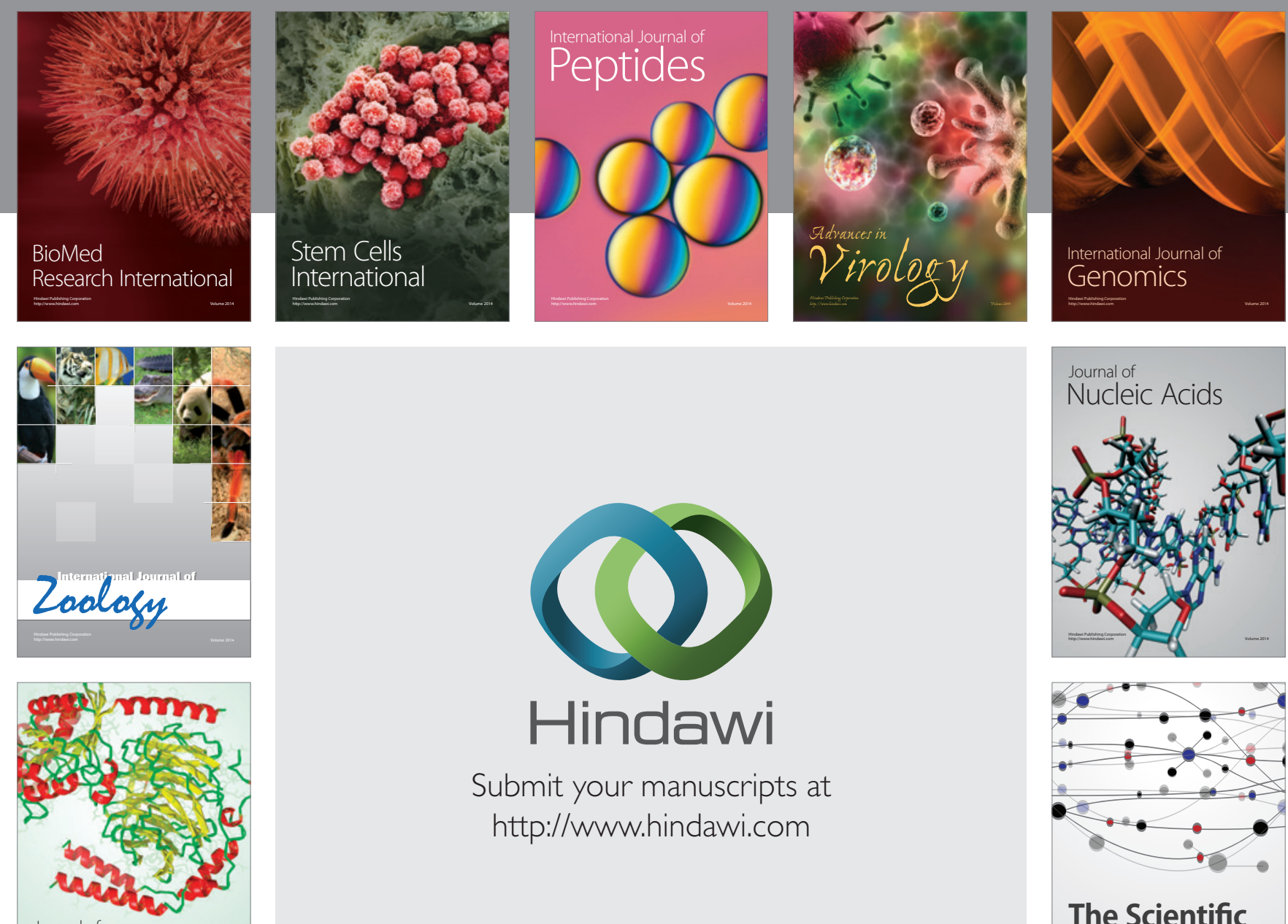

Submit your manuscripts at

http://www.hindawi.com

Journal of
Signal Transduction
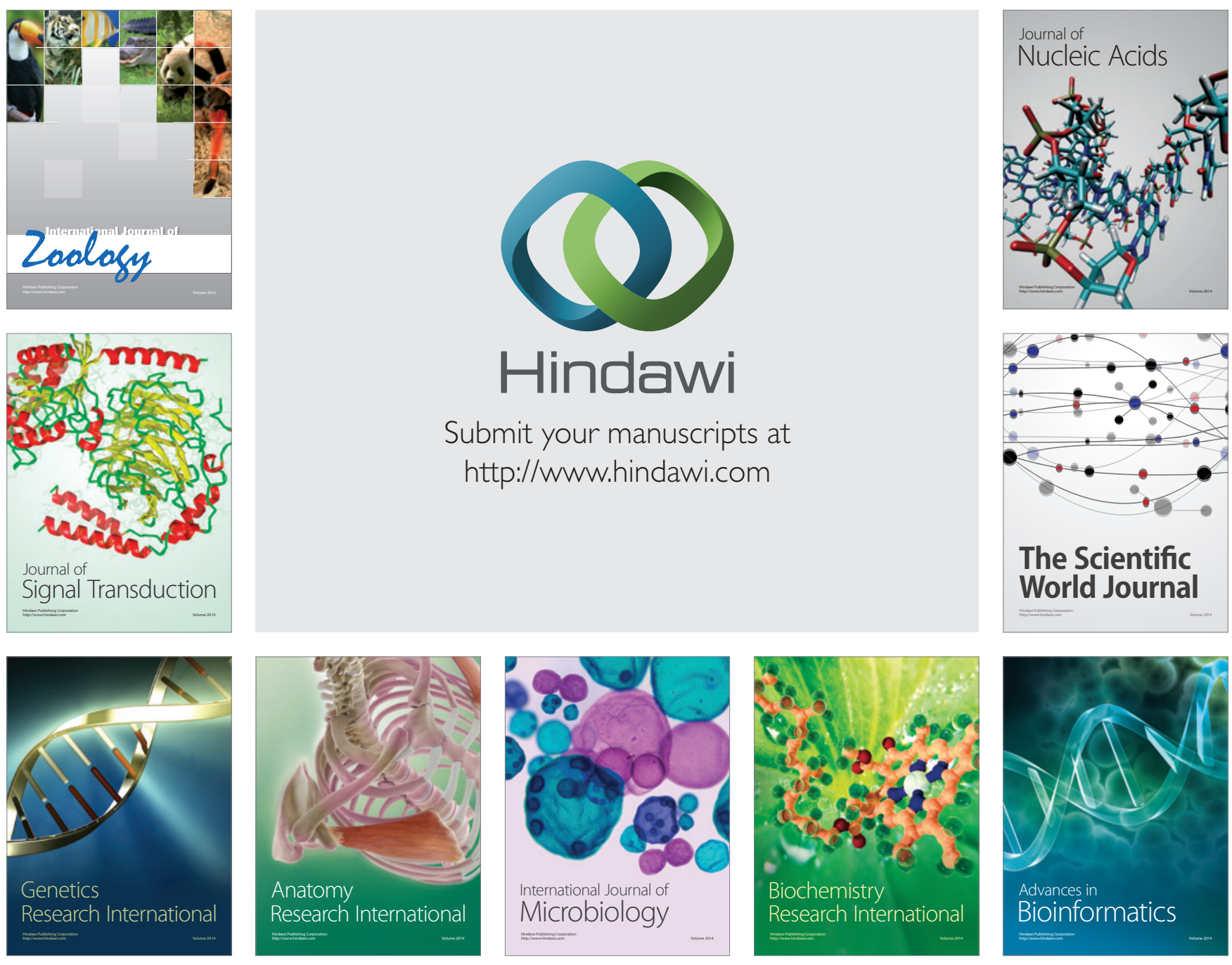

The Scientific World Journal
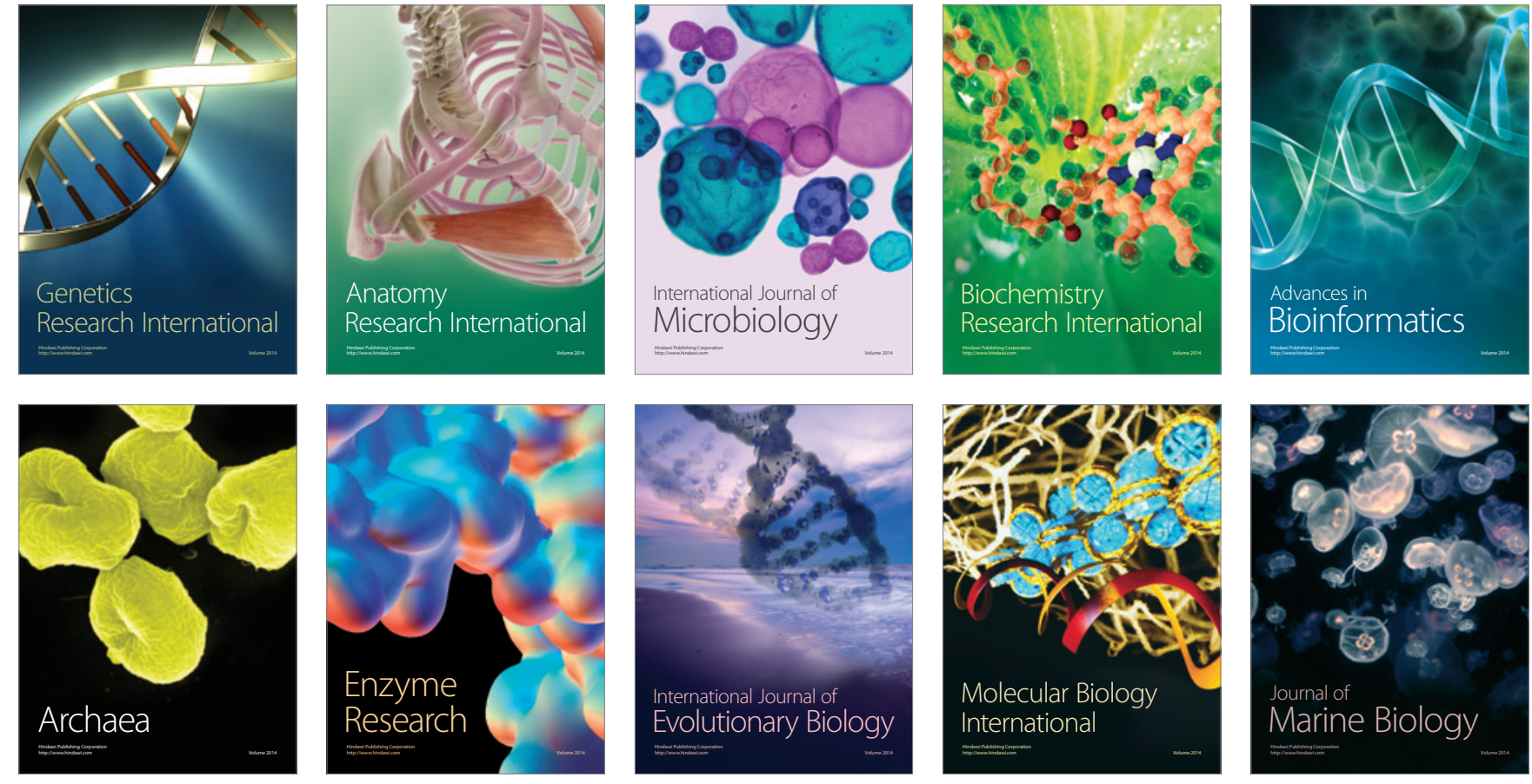